\title{
Anti-KIAA0513 Antibody as a Broad-spectrum Biomarker of Mortal Atherosclerotic and Cancerous Diseases
}

Takaki Hiwasa ( $\nabla$ hiwasa_takaki@faculty.chiba-u.jp )

Chiba University https://orcid.org/0000-0002-0475-3881

Shu-Yang Li

Chiba University: Chiba Daigaku

Masaaki Kubota

Chiba University: Chiba Daigaku

Bo-Shi Zhang

Chiba University: Chiba Daigaku

Yoichi Yoshida

Chiba University: Chiba Daigaku

Eiichi Kobayashi

Chiba University: Chiba Daigaku

Tomoo Matsutani

Chiba University: Chiba Daigaku

Seiichiro Mine

Chiba University: Chiba Daigaku

Toshio Machida

Chiba University: Chiba Daigaku

Masaaki Ito

Toho University: Toho Daigaku

\section{Satoshi Yajima}

Toho University: Toho Daigaku

Makoto Sumazaki

Toho University: Toho Daigaku

\section{Fumiaki Shiratori}

Toho University: Toho Daigaku

Mikako Shirouzu

RIKEN Center for Biosystems Dynamics Research

Shigeyuki Yokoyama

RIKEN structural Biology Laboratory

Mizuki Sata 
Keio University School of Medicine

Kazumasa Yamagishi

University of Tsukuba

Hiroyasu Iso

Osaka University Graduate School of Midicine

Norie Sawada

National Cancer Center

Shoichiro Tsugane

National Cancer Center

Minoru Takemoto

International University of Health and Welfare: Kokusai Iryo Fukushi Daigaku

Koutaro Yokote

Chiba University: Chiba Daigaku

Yoshio Kobayashi

Chiba University: Chiba Daigaku

Kazuyuki Matsushita

Chiba University: Chiba Daigaku

\section{Sohei Kobayashi}

International University of Health and Welfare: Kokusai Iryo Fukushi Daigaku

Jiro Terada

International University of Health and Welfare: Kokusai Iryo Fukushi Daigaku

Koichiro Tatsumi

Chiba University: Chiba Daigaku

Hirotaka Takizawa

Port Square Kashiwado Clinic

Natsuko Shinmen

Fujikura Kasei Co.

Rika Nakamura

Fujikura Kasei Co.

Hideyuki Kuroda

Fujikura Kasei Co.

Hideaki Shimada

Toho University: Toho Daigaku

Yasuo Iwadate

Chiba University: Chiba Daigaku

\section{Research}


Keywords: atherosclerosis, acute ischemic stroke, diabetes mellitus, cardiovascular disease, solid cancer, antibody biomarker

Posted Date: March 10th, 2021

DOI: https://doi.org/10.21203/rs.3.rs-277178/v1

License: (1) This work is licensed under a Creative Commons Attribution 4.0 International License. Read Full License 


\section{Abstract}

Background: Numerous antibody biomarkers have been reported for cancer and atherosclerosis-related diseases. The major complications of atherosclerosis and diabetes mellitus (DM) are acute ischemic stroke (AIS), cardiovascular disease (CVD), and chronic kidney disease (CKD). Cancer development is accompanied by arterial disorders such as angiogenesis and atherosclerosis, and DM is a risk factor for certain cancers. Atherosclerosis-related diseases and cancers are therefore interrelated and could be detected by a common biomarker.

Methods: We employed the protein array method for the initial screening of antigens and employed the amplified luminescent proximity homogeneous assay-linked immunosorbent assay (AlphaLISA) to evaluate antibody levels in serum samples.

Results: The protein array identified KIAA0513 as an antigen recognized by serum IgG antibodies in the sera of patients with atherosclerosis. We then prepared recombinant glutathione S-transferase-fused KIAA0513 protein. AlphaLISA showed significantly higher serum antibody levels against KIAA0513 protein in patients with AIS, transient ischemic attack, DM, CVD, obstructive sleep apnea syndrome (OSAS), CKD, and solid cancers, such as esophageal, gastric, colon, lung, and breast cancer, than in healthy donors. A receiver operating characteristic (ROC) analysis revealed that the highest areas under the ROC curves of anti-KIAA0513 antibodies were for esophageal cancer, nephrosclerosis-type CKD, and DM. Spearman's correlation analysis revealed that serum anti-KIAA0513 antibody levels were associated with maximum intima-media thickness and plaque score, which are indices of atherosclerosis and stenosis.

Conclusion: Serum anti-KIAA0513 antibody markers appear to be useful for diagnosing AIS, TIA, DM, CVD, OSAS, CKD, and solid cancers and might reflect common arterial alterations leading to atherosclerotic and cancerous diseases.

\section{Background}

In recent years, various disease biomarkers have been discovered, and the development of simple blood tests is underway to determine the pathological condition, predict the onset of disease and its prognosis, and identify preventive/therapeutic targets. In terms of biomarker species, studies have reported enzyme, antigen, and, in recent years, nucleotide markers. However, there are still few reports on antibody markers, which include HSP60 [1], RPA2 [2], SOSTDC1 [3], PDCD11 [4], MMP1, CBX1, CBX5 [5], and DNAJC2 [6] for acute ischemic stroke (AIS); ATP2B4 [7], BMP-1 [2, 7], DHPS [8], SH3BP5 [9], prolyl carboxypeptidase [10], LRPAP1 [11], and ASXL2 [12] for atherosclerosis; nardilysin/NRD1 [13] for acute cardiac syndrome; and TUBB2C [14], insulin [15], glutamic acid decarboxylase [16], adiponectin [17], and GADD34 [18] for diabetes mellitus (DM).

The anti-p53 antibody is a typical antibody biomarker for cancer that has been put into practical use for diagnosing, monitoring, and predicting the prognosis of esophageal cancer (EC) and head and neck 
cancer $[19,20]$. Further application of the serological identification of antigens by cDNA expression cloning and the protein array method have identified autoantibodies against TACSTD2 [21], SLC2A1 [22], TRIM21 [23], myomegalin [24], makorin 1 [25], ECSA [26], cyclin L2 [27], and LRPAP1 [11] for EC; FIR/PUF60 for colorectal cancer (CRC) [28] and gastric cancer (GC) [29]; SH3GL1 [30] and filamin C [31] for glioma; EP300-interacting inhibitor of differentiation 3 for nonfunctional pancreatic neuroendocrine tumors [32]; and coatomer protein complex subunit epsilon/COPE [33], NBL1/DAN [34], and SNX16 [35] for obstructive sleep apnea syndrome (OSAS). Here, we report on serum antibodies against KIAA0513 (s$\mathrm{KIAA0513-Ab)} \mathrm{as} \mathrm{a} \mathrm{broad-spectrum} \mathrm{biomarker} \mathrm{applicable} \mathrm{to} \mathrm{atherosclerosis-related} \mathrm{diseases} \mathrm{such} \mathrm{as}$ ischemic stroke, cardiovascular disease (CVD), chronic kidney disease (CKD), DM, and solid cancers.

\section{Methods}

\section{Patient and control sera}

This study was approved by the Local Ethical Review Board of the Chiba University Graduate School of Medicine (Chiba, Japan), as well as by the review boards of the participating hospitals. Sera were collected from patients who had provided written informed consent. Each serum sample was centrifuged at $3000 \mathrm{~g}$ for $10 \mathrm{~min}$, and the supernatant was stored at $-80^{\circ} \mathrm{C}$ until use, avoiding the repeated freezing/thawing of samples.

Serum samples collected from the patients with AIS, transient ischemic attack (TIA), asymptomatic ischemic stroke (Asympt-Cl), chronic-phase cerebral infarction $(\mathrm{cCl})$, and deep and subcortical white matter hyperintensity (DSWMH) were obtained from Chiba Prefectural Sawara Hospital. The stroke subtypes were determined according to the criteria of the Trial of Org 10172 in the Acute Stroke Treatment classification system [36], and large-artery atherosclerosis and small-artery occlusion (lacune) were included as AIS and ischemic stroke. Samples from patients with DM, CVD, and OSAS were obtained from Chiba University Hospital. CVD included acute myocardial infarction (AMI)and unstable angina (UA). The serum samples of patients with AIS, TIA, and AMI were obtained within 2 weeks after disease onset. Samples collected from patients with CKD were obtained from the Kumamoto cohort [37, 38], whereas those collected from patients with EC, GC, CRC, lung cancer (LC), and breast cancer (BC) were obtained from the Department of Surgery, Toho University Hospital. Serum samples from healthy donors (HDs) were obtained from Chiba University, Port Square Kashiwado Clinic, the National Hospital Organization, Shimoshizu Hospital, and Chiba Prefectural Sawara Hospital. For comparisons with TIA and AIS, serum samples from HDs were selected from patients who exhibited no abnormalities in cranial magnetic resonance imaging.

\section{ProtoArray® screening}

The initial screening was performed using ProtoArray ${ }^{\circledR}$ Human Protein Microarrays v4.0 (Thermo Fisher Scientific, Waltham, MA), which were loaded with 9480 species of proteins, as described previously [9]. In total, we employed 20 serum samples (10 each from the patients and HDs) to detect antigens specifically recognized by IgG antibodies in the patient sera. 


\section{Expression and purification of KIAA0513 protein}

We cloned a sequence encoding cDNA of the isoform c of human KIAA0513 (accession number: NP_001284695.1) into pGEX-6P (Cytiva, Pittsburgh, PA). We induced expression of the cDNA product by treating Escherichia coli (E. coli) KRX (Promega, Madison, WI) cells harboring the pGEX-6P-KIAA0513 and pMINOR with $0.5 \mathrm{mM}$ isopropyl- $\beta$-D-thiogalactoside at $37^{\circ} \mathrm{C}$ for $3 \mathrm{~h}$ [39]. The cells were lysed by sonication in phosphate-buffered saline containing $2 \mathrm{mM}$ dithiothreitol. The proteins were purified using Glutathione-Sepharose 4 Fast Flow medium (Cytiva) and HiPrep 26/10 Desalting column (Cytiva).

Purified glutathione S-transferase (GST)-KIAA0513 was concentrated to $3.5 \mathrm{mg} / \mathrm{ml}$ in phosphate-buffered saline containing $2 \mathrm{mM}$ dithiothreitol.

\section{Western blotting}

Purified GST-KIAA0513 and the control GST proteins were electrophoresed through sodium dodecyl sulphate-polyacrylamide (11\%) gels, followed by blotting onto nitrocellulose membranes. The membranes were blocked with $0.1 \%$ dry milk in $150 \mathrm{mM} \mathrm{NaCl}, 20 \mathrm{mM}$ Tris- $\mathrm{HCl}(\mathrm{pH} 7.6)$, and $0.1 \%$ Tween20 (TBS-T) and then treated with anti-GST, anti-KIAA0513, or the patients' sera overnight. The membranes were washed 5 times with TBS-T and treated with HRP-conjugated secondary antibodies for 20 min. After 5 washes with TBS-T, the addition of Immobilon (Merck KGaA, Darmstadt, Germany) produced luminescence, which was detected by LuminoGraph II (Atto, Tokyo, Japan), as described previously $[5,6$, 11].

\section{Amplified luminescence proximity homogeneous assay- linked immunosorbent assay (AlphaLISA)}

AlphaLISA was performed in 384-well microtiter plates (white opaque OptiPlate ${ }^{\mathrm{TM}}$, Perkin Elmer, Waltham, MA) containing either $2.5 \mu \mathrm{L}$ of 1:100-diluted serum with $2.5 \mu \mathrm{L}$ of GST or GST-KIAA0513 proteins (10 $\mu \mathrm{g} / \mathrm{mL}$ ) in AlphaLISA buffer (25 mM N-2-hydroxyethylpiperazine-N-2-ethane sulfonic acid, $\mathrm{pH} 7.4,0.1 \%$ casein, $0.5 \%$ Triton X-100, $1 \mathrm{mg} / \mathrm{mL}$ dextran-500, and 0.05\% ProClin-300). We incubated the reaction mixture at room temperature for $6-8 \mathrm{~h}$, then added anti-human IgG-conjugated acceptor beads $(2.5 \mu \mathrm{L}$ at $40 \mu \mathrm{g} / \mathrm{mL})$ and glutathione-conjugated donor beads $(2.5 \mu \mathrm{L}$ at $40 \mu \mathrm{g} / \mathrm{mL})$, and incubated the mixture at room temperature in the dark for 1-14 days. We measured the chemical emissions using an EnSpire Alpha microplate reader (PerkinElmer), as described previously [5-12]. We calculated the specific reactions by subtracting the emission counts of the GST control from the counts of GST-fusion proteins.

\section{Immunohistochemical staining}

The formalin-fixed paraffin-embedded EC tissues were sectioned into 4- $\mu \mathrm{m}$-thick slices, which were deparaffinized, blocked with Hyper Peroxide Block and Protein Block (Rabbit Specific HRP/DAB Detection Kit, Abcam, Cambridge, UK), reacted with primary anti-KIAA0513 antibodies (rabbit polyclonal antibodies, Atlas Antibodies, Bromma, Sweden) at $0.75 \mu \mathrm{g} / \mathrm{mL}$ for $18 \mathrm{~h}$ at $4^{\circ} \mathrm{C}$, incubated with biotinylated anti-rabbit IgG, and reacted with streptavidin conjugated to horseradish peroxidase reagent (Streptavidin Peroxidase, Abcam). Lastly, we visualized the reaction with a chromogen (diaminobenzidine) in DAB Substrate 
(Abcam). We then counterstained the sections with hematoxylin, dehydrated them, and mounted them as described [11].

\section{Nested case-control study}

We conducted a nested case-cohort study using the abovementioned AlphaLISA detection antibody levels. This study was nested within the Japan Public Health Center-based Prospective Study [40-42], which involved approximately 30,000 Japanese individuals aged 40-69 years at a baseline period from 1990-1994 who had provided informed consent. The serum samples employed were from 202 cases of incidental AIS in the cohort that occurred between baseline and 2008 and from 202 controls whose age (within 2 years), sex, date of blood sampling (within 3 months), time since last meal (within 4 h), and study location (Public Health Center area) were matched with those of the cases. We used a conditional logistic regression model to estimate the odds ratios (ORs) and 95\% confidence intervals (95\% Cls).

\section{Statistical analysis}

We employed the Mann-Whitney $U$ test to determine the significant differences between 2 groups and the Kruskal-Wallis test (Mann-Whitney U test with Bonferroni correction applied) to evaluate the differences among $\geq 3$ groups. We calculated the correlations using Spearman's correlation analysis and logistic regression analysis. All the statistical analyses were performed using GraphPad Prism 5 (GraphPad Software, Inc.). We assessed the predictive values of the putative disease markers via a receiver operating characteristic (ROC) curve analysis and set the cutoff values to maximize the sums of sensitivity and specificity. We evaluated patient survival using the Kaplan-Meier method and compared them using the log-rank test. All tests were 2 -tailed, and $P$-values $<0.05$ were considered to indicate statistically significant differences.

\section{Results}

\section{Recognition of KIAA0513 by serum components from patients with atherosclerosis}

We employed a ProtoArray loaded with 9480 protein species to identify the antigens recognized by antibodies in the sera of patients with atherosclerosis. We found that KIAA0513 isoform c (Accession Number: BC030280.1) reacted with 6 of the 10 serum samples from the patients with atherosclerosis and with only 1 of the 10 samples from the HDs. Subsequently, GST-fused full-length KIAA0513 protein was expressed in $E$. coli and purified by affinity-chromatography.

\section{Presence of autoantibodies against KIAA0513 in the sera of patients with AIS, TIA, DM, EC, or CC}


We examined the presence of autoantibodies against KIAA0513 in sera by Western blotting (Fig. 1). GSTKIAA0513 protein reacted with commercial anti-GST and anti-KIAA0513 antibodies, whereas the control GST reacted with anti-GST but not with anti-KIAA0513 antibodies. GST-KIAA0513 protein was also recognized by serum IgG antibodies in the patients with AIS (\#07065 and \#070684), TIA (\#02337), DM (\#22226), EC (\#EC-6), and CRC (\#Co-58) but not in the HDs (\#09101). GST alone showed no apparent reaction with any serum from the patients or HDs.

\section{Elevation of s-KIAA0513-Abs levels in the patients with AIS and TIA}

We then examined the s-KIAA0513-Abs levels in the patients with AIS or TIA. Sera from HDs and patients with AIS and TIA were obtained from Chiba Prefectural Sawara Hospital. The AlphaLISA results revealed that s-KIAA0513-Ab levels were significantly higher in the patients with AIS or TIA than in the HDs

(Fig. 2a). Using the cutoff values of the average plus 2 standard deviations (SDs) of the HD values, the sKIAA0513-Ab positivity rates for the HDs, patients with AIS, and those with TIA were $0.0 \%, 7.6 \%$, and $15.6 \%$, respectively (Table 1). The ROC analysis revealed that the areas under the ROC curves (AUCs) of sKIAA0513-Abs were 0.6439 (95\% Cl 0.587-0.700) for AIS (Fig. 2b) and 0.6604 (95\% Cl 0.563-0.758) for TIA (Fig. 2C). Thus, TIA (which can be a prodromal stage of AIS) and AIS were equally associated with the s-KIAA0513-Ab marker. 
Table 1

Comparison of the serum antibody levels of healthy donors (HDs) vs. those of patients with acute ischemic stroke (AIS) or transient ischemic attack (TIA).

\begin{tabular}{|c|c|c|c|c|}
\hline \multicolumn{2}{|c|}{ Sample information } & \multirow{2}{*}{$\begin{array}{l}\text { HD } \\
139\end{array}$} & \multirow{2}{*}{$\begin{array}{l}\text { AIS } \\
228\end{array}$} & \multirow{2}{*}{$\begin{array}{l}\text { TIA } \\
44\end{array}$} \\
\hline & Total sample number & & & \\
\hline & Male/Female & $87 / 52$ & $129 / 99$ & $24 / 20$ \\
\hline & Age (Average \pm SD) & $51.6 \pm 12.8$ & $77.0 \pm 11.1$ & $68.5 \pm 12.1$ \\
\hline Subject group & Type of value & KIAA0513-Ab & & \\
\hline \multirow[t]{5}{*}{ HD } & Average & 92,849 & & \\
\hline & SD & 36,115 & & \\
\hline & Cutoff value & 165,080 & & \\
\hline & Positive number & 0 & & \\
\hline & Positive (\%) & $0.0 \%$ & & \\
\hline \multirow[t]{5}{*}{ AIS } & Average & 110,913 & & \\
\hline & SD & 40,351 & & \\
\hline & Positive number & 11 & & \\
\hline & Positive (\%) & $7.6 \%$ & & \\
\hline & $P($ AIS vs HD) & $<0.001$ & & \\
\hline \multirow[t]{5}{*}{ TIA } & Average & 122,303 & & \\
\hline & SD & 42,845 & & \\
\hline & Positive number & 5 & & \\
\hline & Positive (\%) & $15.6 \%$ & & \\
\hline & $P($ TIA vs HD) & $<0.01$ & & \\
\hline \multicolumn{5}{|c|}{$\begin{array}{l}\text { Upper panel indicates the numbers of total samples and samples from male and female samples as } \\
\text { well as ages [average } \pm \text { standard deviation (SD)]. The lower panel summarizes the serum antibody } \\
\text { levels (Alpha photon counts) examined by AlphaLISA using purified KIAA0513-GST protein as an } \\
\text { antigen. Cutoff values were determined as the average HD values plus two SD, and positive samples } \\
\text { higher than the cutoff value were scored. } P \text { values were calculated using the Kruskal-Wallis test. } P \\
\text { values }<0.05 \text { and positive rates }>10 \% \text { are marked in bold text. A scatter dot plot of the same results is } \\
\text { shown in Fig. } 2 \text { a. }\end{array}$} \\
\hline
\end{tabular}

\section{Elevation of serum antibody levels against KIAA0513 in patients with DM}


We next examined the s-KIAA0513-Abs levels in the patients with DM. Serum samples from HDs and patients with DM were obtained from Chiba University and Chiba University Hospital. The s-KIAA0513Abs levels were significantly higher in the samples from the patients with DM than in those from HDs (Fig. 3a). At a cutoff value equivalent to the average plus 2 SDs of the HD specimen values, the positive rates of S-KIAA0513-Ab in the HDs and patients with DM were $2.5 \%$ and $26.5 \%$, respectively (Table 2). We performed an ROC analysis to evaluate the ability of these antibody markers to indicate the presence of DM. The AUC for s-KIAA0513-Abs was 0.736 , yielding a sensitivity and specificity of $50.55 \%$ and $87.65 \%$, respectively (Fig. 3b).

Table 2

Comparison of the serum antibody levels of HDs vs. those of patients with diabetes mellitus (DM).

\begin{tabular}{|c|c|c|c|}
\hline \multicolumn{2}{|l|}{ Sample information } & \multirow{2}{*}{$\begin{array}{l}\text { HD } \\
81\end{array}$} & \multirow{2}{*}{$\begin{array}{l}\text { DM } \\
275\end{array}$} \\
\hline & Total sample number & & \\
\hline & Male/Female & $46 / 35$ & $158 / 117$ \\
\hline & Type 1 DM/Type 2 DM & - & $26 / 216^{\star}$ \\
\hline & Age (Average \pm SD) & $45.2 \pm 11.0$ & $63.1 \pm 12.0$ \\
\hline Subject group & Type of value & KIAA0513-Ab & \\
\hline \multirow[t]{5}{*}{$\mathrm{HD}$} & Average & 33,698 & \\
\hline & SD & 18,121 & \\
\hline & Cutoff value & 69,941 & \\
\hline & Positive number & 2 & \\
\hline & Positive (\%) & $2.5 \%$ & \\
\hline \multirow[t]{5}{*}{ DM } & Average & 55,282 & \\
\hline & SD & 29,897 & \\
\hline & Positive number & 73 & \\
\hline & Positive (\%) & $26.5 \%$ & \\
\hline & $P($ vs HD) & $<0.001$ & \\
\hline $\begin{array}{l}\text { The upper panel indic } \\
\text { and samples from pa } \\
\text { panel summarizes the } \\
\text { protein as an antigen } \\
\text { shown in Fig. } 2 a .{ }^{*} 33\end{array}$ & $\begin{array}{l}\text { es the numbers of total } \\
\text { ents with type } 1 \text { and type } \\
\text { serum antibody levels exa } \\
\text { s described in the legend } \\
\text { ad undetermined DM. }\end{array}$ & $\begin{array}{l}\text { pples from ma } \\
\text { l as ages (ave } \\
\text { phaLISA usino } \\
\text { l scatter dot pl }\end{array}$ & $\begin{array}{l}\text { male subjects, } \\
\text {. The lower } \\
\text { KIAA0513-GST } \\
\text { same results is }\end{array}$ \\
\hline
\end{tabular}




\section{Association between s-KIAA0513-Abs levels and CVD and OSAS}

Next, we examined the antibody levels in serum samples from patients with CVD obtained from Chiba University Hospital. Given that OSAS is related to atherosclerosis and is associated with a high risk of AIS and CVD [33 - 36], we also examined the sera of patients with OSAS obtained from Chiba University Hospital. Compared with those of the HDs, the s-KIAA0513-Abs levels were significantly higher in the patients with CVD or OSAS (Fig. 4a), although the positive rates in the patients with CVD and those with OSAS were not so high ( $10.3 \%$ and $11.6 \%$, respectively) (Table 3$)$. The ROC analysis revealed that the sKIAA0513-Abs AUCs for CVD and OSAS were 0.649 (95\% Cl 0.582-0.716) (Fig. 4b) and 0.646 (95\% Cl $0.562-0.731$ ) (Fig. 4b and 4c), respectively. Compared with the low $P$-value $(<0.0001)$ of s-KIAA0513-Ab for CVD, the $P$-value for OSAS was 0.001 (Table 3), suggesting a lesser association of the s-KIAA0513-Ab marker with OSAS than with CVD. 
Table 3

Comparison of the serum antibody levels of HDs vs. those of patients with cardiovascular disease (CVD) or obstructive sleep apnea syndrome (OSAS).

\begin{tabular}{|c|c|c|c|c|}
\hline \multicolumn{2}{|c|}{ Sample information } & \multirow{2}{*}{$\begin{array}{l}\text { HD } \\
76\end{array}$} & \multirow{2}{*}{$\begin{array}{l}\text { CVD } \\
97\end{array}$} & \multirow{2}{*}{$\begin{array}{l}\text { OSAS } \\
86\end{array}$} \\
\hline & Total sample number & & & \\
\hline & Male/Female & $43 / 33$ & $81 / 16$ & $59 / 27$ \\
\hline & Age (Average \pm SD) & $45.1 \pm 11.5$ & $66.3 \pm 11.4$ & $57.8 \pm 12.5$ \\
\hline Subject group & Type of value & KIAA0513-Ab & & \\
\hline \multirow[t]{5}{*}{ HD } & Average & 43,398 & & \\
\hline & SD & 21,374 & & \\
\hline & Cutoff value & 86,146 & & \\
\hline & Positive number & 4 & & \\
\hline & Positive (\%) & $5.3 \%$ & & \\
\hline \multirow[t]{5}{*}{ CVD } & Average & 57,531 & & \\
\hline & SD & 22,460 & & \\
\hline & Positive number & 10 & & \\
\hline & Positive (\%) & $10.3 \%$ & & \\
\hline & $P(C V D$ vs HD) & $<0.001$ & & \\
\hline \multirow[t]{5}{*}{ OSAS } & Average & 55,650 & & \\
\hline & SD & 27,493 & & \\
\hline & Positive number & 10 & & \\
\hline & Positive (\%) & $11.6 \%$ & & \\
\hline & $\mathrm{P}$ (OSAS vs HD) & $<0.01$ & & \\
\hline
\end{tabular}

\section{Elevation of s-KIAA0513-Abs levels in patients with CKD}

We next examined the antibody levels in the sera of patients with CKD, which is also closely related to atherosclerosis. CKD was divided into 3 groups as follows: type 1, diabetic kidney disease; type 2, nephrosclerosis; and type 3, glomerulonephritis. Samples from patients with CKD were obtained from the 
Kumamoto cohort, and samples from HDs were obtained from Chiba University. Patients from all 3 CKD groups had significantly higher serum s-KIAA0513-Abs levels than the HDs (Fig. 5a). The s-KIAA0513-Ab positivity rates in the HDs and patients with types 1, 2, and 3 CKD were $6.1 \%, 29.0 \%, 37.5 \%$, and $20.3 \%$, respectively (Table 4), indicating that the highest positive rate was observed in the patients with type 2 CKD. The ROC analysis revealed s-KIAA0513-Abs AUCs as high as 0.7434 (95\% $\mathrm{Cl} 0.678-0.809)$ for type 1 CKD (Fig. 5b), 0.808 (95\% Cl 0.726-0.890) for type 2 CKD (Fig. 5c), and 0.691 (95\% Cl 0.618-0.764) for type 3 CKD (Fig. 5d). 
Table 4

Comparison of s-KIAA0513-Ab levels of HDs versus those of patients with chronic kidney disease (CKD).

Sample information

Total sample number

Male/Female

Age (Average \pm SD)

Alpha analysis (antibody level)

HD

SD

Cutoff value

Positive No.

Positive rate (\%)

Average

SD

Positive No.

Positive rate (\%)

$P$ (vs HD)

Average

SD

Positive No.

Positive rate (\%)

$P$ (vs HD)

Type-3 CKD

Average

SD

Positive No.

Positive rate (\%)

$P$ (vs HD)
HD

82

$44 / 38$

$44.1 \pm 11.2$

KIAA0513-Ab

36,007

28,697

93,400

5

$6.1 \%$

71,773

44,434

42

$29.0 \%$

$<0.001$

84,954

47,414

12

$37.5 \%$

$<0.001$

61,443

41,110

25

$20.3 \%$

$<0.001$

Types-1, -2, and - 3 CKDs correspond to diabetic kidney disease, nephrosclerosis, and glomerulonephritis, respectively. The upper panel indicates the numbers of all samples and samples from males and females as well as age (average $\pm S D$ ). The lower panel summarizes the serum antibody levels examined by AlphaLISA using purified KIAA0513-GST protein as an antigen as described in the legend of Table 1. A scatter dot plot of the same results is shown in Fig. 4a. 


\section{s-KIAA0513-Ab levels in solid cancer}

Given that atherosclerotic diseases are frequently related to cancer with certain common biomarkers being reported [17], we examined the serum samples from patients with EC, GC, CRC, LC, and BC obtained from Toho University Hospital. The s-KIAA0513-Abs levels were significantly higher in the samples from all patients with cancer than in those from the HDs (Fig. 6a, Table 5). The highest average value and positive rate of s-KIAA0513-Ab levels were observed for EC (Table 5). Likewise, the AUC values were highest for EC (0.830) and lowest for BC among the cancers examined (Fig. 6b-6f, Table 6). 
Table 5

Comparison of s-KIAA0513-Ab levels between HDs and patients with cancer.

\begin{tabular}{|c|c|c|c|c|c|c|c|}
\hline \multicolumn{2}{|c|}{ Sample information } & HD & EC & GC & $\mathrm{CC}$ & LC & MC \\
\hline & $\begin{array}{l}\text { Total sample } \\
\text { number }\end{array}$ & 96 & 192 & 96 & 192 & 96 & 96 \\
\hline & Male/Female & $51 / 45$ & $155 / 37$ & $68 / 28$ & $119 / 74$ & $0 / 96$ & $58 / 38$ \\
\hline & $\begin{array}{l}\text { Age (Average } \pm \\
\text { SD) }\end{array}$ & $57.9 \pm 6.0$ & $\begin{array}{l}67.4 \pm \\
9.8\end{array}$ & $\begin{array}{l}68.7 \pm \\
10.6\end{array}$ & $\begin{array}{l}66.7 \pm \\
11.7\end{array}$ & $\begin{array}{l}60.9 \pm \\
13.3\end{array}$ & $\begin{array}{l}68.1 \pm \\
9.6\end{array}$ \\
\hline $\begin{array}{l}\text { Subject } \\
\text { group }\end{array}$ & Type of value & $\begin{array}{l}\text { KIAA0513- } \\
\mathrm{Ab}\end{array}$ & & & & & \\
\hline \multirow[t]{5}{*}{ HD } & Average & 36,199 & & & & & \\
\hline & SD & 23,001 & & & & & \\
\hline & Cutoff value & 82,201 & & & & & \\
\hline & Positive number & 8 & & & & & \\
\hline & Positive (\%) & $8.3 \%$ & & & & & \\
\hline \multirow[t]{5}{*}{ EC } & Average & 87,535 & & & & & \\
\hline & SD & 57,134 & & & & & \\
\hline & Positive number & 86 & & & & & \\
\hline & Positive (\%) & $44.8 \%$ & & & & & \\
\hline & $\mathrm{P}$ (EC vs HD) & $<0.001$ & & & & & \\
\hline \multirow[t]{5}{*}{ GC } & Average & 62,714 & & & & & \\
\hline & SD & 54,540 & & & & & \\
\hline & Positive number & 21 & & & & & \\
\hline & Positive (\%) & $21.9 \%$ & & & & & \\
\hline & P (GC vs HD) & $<0.001$ & & & & & \\
\hline \multirow[t]{3}{*}{ CRC } & Average & 69,308 & & & & & \\
\hline & SD & 58,449 & & & & & \\
\hline & Positive number & 53 & & & & & \\
\hline
\end{tabular}

Types of cancer diagnoses included esophageal cancer (EC), gastric cancer (GC), colon cancer (CC), lung cancer (LC), and breast cancer (BC). Purified KIAA0513 (2-302)-GST protein was used as antigen. Cutoff values were determined as the average HD values plus two SDs. $P$ values were calculated by comparing the results of HDs and patients using the Kruskal-Wallis test. $P$ values $<0.05$ and positive rates $>10 \%$ are marked in bold text. A scatter dot plot of the same results is shown in Fig. 5a. 


\begin{tabular}{|c|c|c|c|c|c|c|c|}
\hline \multicolumn{2}{|c|}{ Sample information } & HD & EC & GC & $\mathrm{CC}$ & LC & MC \\
\hline & Positive (\%) & \multicolumn{6}{|l|}{$27.6 \%$} \\
\hline & P (CRC vs HD) & \multicolumn{6}{|l|}{$<0.001$} \\
\hline \multirow[t]{5}{*}{ LC } & Average & \multicolumn{6}{|l|}{62,148} \\
\hline & SD & \multicolumn{6}{|l|}{57,101} \\
\hline & Positive number & \multicolumn{6}{|l|}{24} \\
\hline & Positive (\%) & \multicolumn{6}{|l|}{$25.0 \%$} \\
\hline & P (LC vs HD) & \multicolumn{6}{|l|}{$<0.001$} \\
\hline \multirow[t]{5}{*}{$\mathrm{BC}$} & Average & \multicolumn{6}{|l|}{50,270} \\
\hline & SD & \multicolumn{6}{|l|}{36,802} \\
\hline & Positive number & \multicolumn{6}{|l|}{18} \\
\hline & Positive (\%) & \multicolumn{6}{|l|}{$18.8 \%$} \\
\hline & P (MC vs HD) & \multicolumn{6}{|l|}{0.002} \\
\hline \multicolumn{8}{|c|}{$\begin{array}{l}\text { Types of cancer diagnoses included esophageal cancer (EC), gastric cancer (GC), colon cancer (CC), } \\
\text { lung cancer (LC), and breast cancer (BC). Purified KIAA0513 (2-302)-GST protein was used as antigen } \\
\text { Cutoff values were determined as the average HD values plus two SDs. P values were calculated by } \\
\text { comparing the results of HDs and patients using the Kruskal-Wallis test. } P \text { values }<0.05 \text { and positive } \\
\text { rates }>10 \% \text { are marked in bold text. A scatter dot plot of the same results is shown in Fig. } 5 \text { a. }\end{array}$} \\
\hline
\end{tabular}


Table 6

Receiver operating characteristic (ROC) analysis.

\begin{tabular}{|c|c|c|c|c|c|}
\hline & AIS & TIA & DM & CVD & OSAS \\
\hline AUC value & 0.6439 & 0.6604 & 0.7361 & 0.6492 & 0.6463 \\
\hline $\begin{array}{l}\text { Cutoff } \\
\text { value }\end{array}$ & > 108861 & $>106592$ & $>50364$ & $>63974$ & $>40530$ \\
\hline $\begin{array}{l}\text { Sensitivity } \\
(\%)\end{array}$ & 57.02 & 63.64 & 50.55 & 34.18 & 73.26 \\
\hline $\begin{array}{l}\text { Specificity } \\
(\%)\end{array}$ & 67.63 & 64.75 & 87.65 & 89.47 & 52.63 \\
\hline $95 \% \mathrm{Cl}$ & $\begin{array}{l}0.5873 \text { to } \\
0.7004\end{array}$ & $\begin{array}{l}0.5633 \text { to } \\
0.7575\end{array}$ & $\begin{array}{l}0.6789 \text { to } \\
0.7933\end{array}$ & $\begin{array}{l}0.5821 \text { to } \\
0.7163\end{array}$ & $\begin{array}{l}0.5616 \text { to } \\
0.7309\end{array}$ \\
\hline \multirow[t]{2}{*}{$P$ value } & $<0.0001$ & 0.0014 & $<0.0001$ & $<0.0001$ & 0.0013 \\
\hline & Type-1 CKD & Type-2 CKD & Type-3 CKD & & \\
\hline AUC value & 0.7434 & 0.8080 & 0.6906 & & \\
\hline $\begin{array}{l}\text { Cutoff } \\
\text { value }\end{array}$ & $>47004$ & $>29559$ & $>43344$ & & \\
\hline $\begin{array}{l}\text { Sensitivity } \\
(\%)\end{array}$ & 65.52 & 100.00 & 63.41 & & \\
\hline $\begin{array}{l}\text { Specificity } \\
(\%)\end{array}$ & 73.81 & 50.00 & 69.05 & & \\
\hline $95 \% \mathrm{Cl}$ & $\begin{array}{l}0.6783 \text { to } \\
0.8085\end{array}$ & $\begin{array}{l}0.7264 \text { to } \\
0.8897\end{array}$ & $\begin{array}{l}0.6177 \text { to } \\
0.7635\end{array}$ & & \\
\hline \multirow[t]{2}{*}{$P$ value } & $<0.0001$ & $<0.0001$ & $<0.0001$ & & \\
\hline & EC & $\mathrm{GC}$ & CRC & LC & $\mathrm{MC}$ \\
\hline AUC value & 0.8300 & 0.6772 & 0.7279 & 0.6513 & 0.6076 \\
\hline $\begin{array}{l}\text { Cutoff } \\
\text { value }\end{array}$ & $>48378$ & $>47940$ & $>43924$ & $>48049$ & $>46726$ \\
\hline $\begin{array}{l}\text { Sensitivity } \\
(\%)\end{array}$ & 72.92 & 55.21 & 61.98 & 50.00 & 41.67 \\
\hline $\begin{array}{l}\text { Specificity } \\
(\%)\end{array}$ & 80.21 & 79.17 & 75.00 & 80.21 & 78.13 \\
\hline $95 \% \mathrm{Cl}$ & $\begin{array}{l}0.7818 \text { to } \\
0.8782\end{array}$ & $\begin{array}{l}0.6009 \text { to } \\
0.7535\end{array}$ & $\begin{array}{l}0.6681 \text { to } \\
0.7876\end{array}$ & $\begin{array}{l}0.5736 \text { to } \\
0.7289\end{array}$ & $\begin{array}{l}0.5281 \text { to } \\
0.6872\end{array}$ \\
\hline $\begin{array}{l}\text { Area under } \\
(\%) \text {, and } P \vee \\
\text { antigen. } P v\end{array}$ & $\begin{array}{l}\text { curve (AUC), } \\
\text { e of the ROC } \\
\text { es lower thar }\end{array}$ & $\begin{array}{l}\text { confidence in } \\
\text { sis are shou } \\
\text { and AUCs h }\end{array}$ & $\begin{array}{l}\text { I }(95 \% \mathrm{Cl}) \text {, cu } \\
\text { urified } \mathrm{GST}-\mathrm{KI} \\
\text { than } 0.7 \text { are }\end{array}$ & $\begin{array}{l}\text { value, sens } \\
13 \text { protein } \\
\text { ed in bold. }\end{array}$ & $\begin{array}{l}\%), \text { specificit } \\
\text { sed as an }\end{array}$ \\
\hline
\end{tabular}




\begin{tabular}{|c|c|c|c|c|c|}
\hline & AIS & TIA & DM & CVD & OSAS \\
\hline$P$ value & $<0.0001$ & $<0.0001$ & $<0.0001$ & 0.0003 & 0.0100 \\
\hline
\end{tabular}

We then examined whether s-KIAA0513-Ab levels are related to the postoperative survival of patients with EC or GC. We divided the s-KIAA0513-Ab levels into positive and negative groups using the cutoff values obtained by the ROC analysis (Fig. 6b, 6c). Although there were no significant differences in overall survival between the s-KIAA0513-Ab-positive and negative EC groups $(P=0.351)$, the antibody-positive group presented a poor prognosis in the late postoperative stage (40-60 weeks) (Fig. 7a). In contrast, there was no apparent difference in survival between the s-KIAA0513-Ab-positive and negative GC groups (Fig. 7b).

We examined the expression levels of KIAA0513 antigenic protein in EC tissues using immunohistochemical staining. Figure 7c shows representative examples of the staining. EC tissues were heavily stained by anti-KIAA0513 antibody, whereas surrounding healthy esophageal tissues were not. KIAA0513 protein was localized in the cytoplasm, which is consistent with a previous report [43]. Thus, the high KIAA0513 expression levels might account for some, if not all, of the development of serum KIAA0513-Abs.

\section{Correlation analysis}

We performed a correlation analysis of s-KIAA0513-Ab levels and participant data using 665 specimens from Chiba Prefectural Sawara Hospital, including 139 specimens from HDs, 225 from patients with AIS, 44 from patients with TIA, 17 from patients with Asympt-Cl, 122 from patients with DSWMH, 59 from patients with $\mathrm{cCl}$, and 41 from disease controls. In this analysis, we employed the Mann-Whitney $U$ test to compare s-KIAA0513-Ab levels between the male and female participants, with or without DM, hypertension, CVD, dyslipidemia, and obesity [body mass index $(\mathrm{BMI}) \geq 25$ ] and with or without smoking and alcohol intake habits. We observed a significant difference in s-KIAA0513-Ab levels only between the patients with hypertension and those without hypertension (Table 7). 
Table 7

Correlation analysis of antibody levels against KIAA0513 protein with data of subjects in the Sawara Hospital cohort

\begin{tabular}{|c|c|c|c|}
\hline Sex & & Male & Female \\
\hline Sample number & & 396 & 268 \\
\hline \multirow[t]{2}{*}{ KIAA0513-Ab level } & Average & 10,136 & 104,138 \\
\hline & SD & 39,889 & 40,969 \\
\hline$P$ value (vs Male) & & & 0.1466 \\
\hline Other disease & & DM- & $\mathrm{DM}+$ \\
\hline Sample number & & 525 & 135 \\
\hline \multirow[t]{2}{*}{ KIAA0513-Ab level } & Average & 101,818 & 101,727 \\
\hline & SD & 40,022 & 41,930 \\
\hline$P$ value (vs DM-) & & & 0.5031 \\
\hline Other disease & & HT- & $\mathrm{HT}+$ \\
\hline Sample number & & 239 & 421 \\
\hline \multirow[t]{2}{*}{ KIAA0513-Ab level } & Average & 96,476 & 104,821 \\
\hline & SD & 38,988 & 40,905 \\
\hline$P$ value (vs HT-) & & & 0.0091 \\
\hline Other disease & & CVD- & CVD+ \\
\hline Sample number & & 623 & 37 \\
\hline \multirow[t]{2}{*}{ KIAA0513-Ab level } & Average & 101,376 & 108,939 \\
\hline & SD & 39,757 & 49,697 \\
\hline$P$ value (vs CVD-) & & & 0.1177 \\
\hline Other disease & & Lipidemia- & Lipidemia+ \\
\hline Sample number & & 475 & 185 \\
\hline \multirow[t]{2}{*}{ KIAA0513-Ab level } & Average & 103,028 & 98,647 \\
\hline & SD & 40,591 & 39,808 \\
\hline
\end{tabular}

The subjects were divided as follows: sex (male and female); presence (+) or absence $(-)$ of complication of DM, hypertension (HT), CVD, or dyslipidemia, and lifestyle factors (smoking and alcohol intake habits). Antibody levels (alpha counts) were compared using the Kruskal-Wallis test (upper panel) and the Mann-Whitney U test (lower panels). Sample numbers, averages and SDs of counts as well as $P$ values are shown. Significant correlations $(P<0.05)$ are marked in bold. 


\begin{tabular}{|c|c|c|c|}
\hline Sex & & Male & Female \\
\hline$P$ value (vs Lipidemia-) & & & 0.2716 \\
\hline Obesity & & $\mathrm{BMI}<25$ & $\mathrm{BMI}>25$ \\
\hline Sample number & & 498 & 158 \\
\hline \multirow[t]{2}{*}{ KIAA0513-Ab level } & Average & 102,071 & 101,390 \\
\hline & SD & 40,475 & 40,488 \\
\hline \multicolumn{2}{|l|}{$P$ value (vs Alcohol-) } & & 0.7490 \\
\hline \multicolumn{2}{|l|}{ Life style } & Non-smoker & Smoker \\
\hline \multicolumn{2}{|l|}{ Sample number } & 344 & 319 \\
\hline \multirow[t]{2}{*}{ KIAA0513-Ab level } & Average & 98,991 & 104,832 \\
\hline & SD & 38,563 & 42,055 \\
\hline \multicolumn{3}{|l|}{$P$ value (vs non-smoker) } & 0.0673 \\
\hline \multicolumn{2}{|l|}{ Life style } & Alcohol- & Alcohol+ \\
\hline \multicolumn{2}{|l|}{ Sample number } & 238 & 419 \\
\hline \multirow[t]{2}{*}{ KIAA0513-Ab level } & Average & 102,663 & 101,364 \\
\hline & SD & 39,883 & 40,759 \\
\hline \multicolumn{3}{|l|}{$P$ value (vs Alcohol-) } & 0.4595 \\
\hline \multicolumn{4}{|c|}{$\begin{array}{l}\text { The subjects were divided as follows: sex (male and female); presence }(+) \text { or absence }(-) \text { of } \\
\text { complication of DM, hypertension (HT), CVD, or dyslipidemia, and lifestyle factors (smoking and } \\
\text { alcohol intake habits). Antibody levels (alpha counts) were compared using the Kruskal-Wallis test } \\
\text { (upper panel) and the Mann-Whitney U test (lower panels). Sample numbers, averages and SDs of } \\
\text { counts as well as } P \text { values are shown. Significant correlations }(P<0.05) \text { are marked in bold. }\end{array}$} \\
\hline
\end{tabular}

We performed a Spearman's correlation analysis to determine the correlation between the s-KIAA0513-Ab levels and the continuous variables of participant parameters, including general information such as age, height, weight, and BMl; degree of artery stenosis, including the maximum intima-media thickness (maxIMT); lifestyle factors such as smoking duration (years) and alcohol intake frequency (times/week); and blood test data. Supplementary Table S1 lists the average values of these parameters. There was a significant correlation between s-KIAA013-Abs and age, max-IMT, alkaline phosphatase, potassium, Creactive protein (CRP), body sugar (BS), and smoking duration (Table 8 ) and an inverse relationship with height and weight. The correlation with max-IMT suggests that s-KIAA0513-Ab levels are associated with stenosis and atherosclerosis, which was further confirmed by using other cohorts. A Spearman's correlation analysis of the CKD cohort (300 participants) showed a significant correlation with plaque 
score, max-IMT [44, 45], and cardio-ankle vascular index (CAVI) (right) [46] (Supplementary Table S2), which are indices of atherosclerosis. CRP was also associated with s-KIAA0513-Abs in the CKD cohort, suggesting the involvement of inflammation. In contrast, age, height, weight, BMI, and potassium levels showed no significant correlation with s-KIAA0513-Abs in the CKD cohort. AIS is closely related to age, which might be indirectly associated with s-KIAA0513-Abs. 
Table 8

Correlation analysis of serum antibody levels against KIAA0513 with data on subjects in the Sawara Hospital cohort.

\begin{tabular}{|c|c|c|c|}
\hline \multirow[t]{2}{*}{ Parameter } & \multirow[t]{2}{*}{ Number of $X Y$ pairs } & \multicolumn{2}{|c|}{ KIAA0513-Ab } \\
\hline & & rvalue & $P$ value \\
\hline Age & 663 & 0.1959 & $<0.0001^{* *}$ \\
\hline Height & 657 & -0.1317 & 0.0007 \\
\hline Weight & 661 & -0.1093 & 0.0049 \\
\hline BMI* & 656 & -0.0414 & 0.2899 \\
\hline max-IMT & 457 & 0.1763 & 0.0002 \\
\hline$A / G$ & 628 & -0.0187 & 0.6402 \\
\hline AST (GOT) & 655 & 0.0395 & 0.3134 \\
\hline ALT (GPT) & 655 & -0.0035 & 0.9278 \\
\hline ALP & 600 & 0.0889 & 0.0295 \\
\hline LDH & 631 & 0.0431 & 0.2798 \\
\hline tBil & 637 & 0.0317 & 0.4250 \\
\hline CHE & 506 & -0.0387 & 0.3851 \\
\hline Y-GTP & 609 & -0.0099 & 0.8072 \\
\hline TP & 633 & -0.0184 & 0.6435 \\
\hline ALB & 638 & -0.0207 & 0.6014 \\
\hline BUN & 654 & -0.0454 & 0.2469 \\
\hline CRE & 649 & -0.0310 & 0.4303 \\
\hline eGFR & 552 & 0.0432 & 0.3113 \\
\hline UA & 492 & -0.0138 & 0.7596 \\
\hline AMY & 415 & -0.0901 & 0.0667 \\
\hline $\mathrm{T}-\mathrm{CHO}$ & 563 & -0.0446 & 0.2913 \\
\hline HDL-C & 435 & -0.0280 & 0.5600 \\
\hline TG & 460 & -0.0198 & 0.6719 \\
\hline $\mathrm{Na}$ & 641 & -0.0347 & 0.3808 \\
\hline $\mathrm{K}$ & 641 & -0.0899 & 0.0228 \\
\hline
\end{tabular}




\begin{tabular}{|c|c|c|c|}
\hline \multirow[t]{2}{*}{ Parameter } & \multirow[t]{2}{*}{ Number of $X Y$ pairs } & \multicolumn{2}{|c|}{ KIAA0513-Ab } \\
\hline & & rvalue & $P$ value \\
\hline $\mathrm{Cl}$ & 641 & -0.0392 & 0.3215 \\
\hline $\mathrm{Ca}$ & 380 & -0.0607 & 0.2376 \\
\hline IP & 302 & -0.0085 & 0.8824 \\
\hline $\mathrm{Fe}$ & 311 & -0.0083 & 0.8838 \\
\hline CRP & 477 & 0.0917 & 0.0453 \\
\hline LDL-C & 344 & -0.0559 & 0.3011 \\
\hline WBC & 650 & 0.0712 & 0.0697 \\
\hline RBC & 650 & -0.0220 & 0.5748 \\
\hline HGB & 650 & 0.0117 & 0.7651 \\
\hline $\mathrm{HCT}$ & 650 & -0.0041 & 0.9174 \\
\hline MCV & 650 & 0.0525 & 0.1814 \\
\hline $\mathrm{MCH}$ & 650 & 0.0611 & 0.1199 \\
\hline $\mathrm{MCHC}$ & 650 & 0.0401 & 0.3080 \\
\hline RDW & 650 & 0.0437 & 0.2661 \\
\hline PLT & 650 & -0.0269 & 0.4942 \\
\hline MPV & 650 & -0.0354 & 0.3683 \\
\hline PCT & 650 & -0.0271 & 0.4900 \\
\hline PDW & 650 & -0.0342 & 0.3838 \\
\hline BS & 596 & 0.0932 & 0.0229 \\
\hline $\mathrm{HbA} 1 \mathrm{c}$ & 505 & -0.0212 & 0.6351 \\
\hline Smoking duration & 656 & 0.1297 & 0.0009 \\
\hline Alcohol frequency & 662 & -0.0328 & 0.4000 \\
\hline
\end{tabular}




\begin{tabular}{|c|c|c|c|}
\hline \multirow[t]{2}{*}{ Parameter } & \multirow[t]{2}{*}{ Number of $X Y$ pairs } & \multicolumn{2}{|c|}{ KIAA0513-Ab } \\
\hline & & rvalue & $P$ value \\
\hline \multicolumn{4}{|c|}{$\begin{array}{l}\text { *Subjects' data used were age, height, weight, body mass index (BMI), maximum intima-media } \\
\text { thickness (max-IMT), albumin/globulin ratio (A/G), aspartate aminotransferase (AST), alanine amino } \\
\text { transferase (ALT), alkaline phosphatase (ALP), lactate dehydrogenase (LDH), total bilirubin (tBil), } \\
\text { cholinesterase (CHE), Y-glutamyl transpeptidase (Y-GTP), total protein (TP), albumin (ALB), blood urea } \\
\text { nitrogen (BUN), creatinine (CRE), estimated glomerular filtration rate (eGFR), uric acid (UA), amylase } \\
\text { (AMY), total cholesterol (T-CHO), high-density lipoprotein cholesterol (HDL-C), triglyceride (TG), } \\
\text { sodium (Na), potassium (K), chlorine (Cl), calcium (Ca), inorganic phosphate (IP), iron (Fe), C-reactive } \\
\text { protein (CRP), low-density lipoprotein cholesterol (LDL-C), white blood cell number (WBC), red blood } \\
\text { cell number (RBC), hemoglobin (HGB), hematocrit (HCT), mean corpuscular volume (MCV), mean } \\
\text { corpuscular hemoglobin (MCH), MCH concentration (MCHC), red cell distribution width (RDW), } \\
\text { platelet number (PLT), mean platelet volume (MPV), procalcitonin (PCT), platelet distribution width } \\
\text { (PDW), blood sugar (BS), glycated hemoglobin (HbA1C), smoking duration (year), and alcohol intake } \\
\text { frequency (times/week). }\end{array}$} \\
\hline \multicolumn{4}{|c|}{ **Significant correlations $(P<0.05)$ are marked in bold. } \\
\hline
\end{tabular}

\section{Japan Public Health Center (JPHC) cohort analysis}

We conducted a case-control study nested within the Japan Public Health Center-based Prospective Study, which involved approximately 30,000 plasma samples [40-42]. The level of antibodies against the KIAA0513 protein was positively associated with the risk of AIS. The ORs $(95 \%$ Cls) were $2.11(1.17-$ $3.81)$ and $2.23(1.18-4.21)$ for those in the third and highest quartiles of antibody levels, respectively, compared with those in the lowest quartile (Table 9). These results indicate that the antibody markers against the KIAA0513 protein are useful for predicting the onset of AIS.

Table 9

Odds ratios of incident KIAA0513-Abs versus AIS.

\begin{tabular}{|c|c|c|}
\hline & & KIAA0513-Ab vs AIS \\
\hline \multirow[t]{2}{*}{ 2nd } & Matched OR & 1.69 \\
\hline & $95 \% \mathrm{Cl}$ & $0.91-3.15$ \\
\hline \multirow[t]{2}{*}{$3 r d$} & Matched OR & 2.11 \\
\hline & $95 \% \mathrm{Cl}$ & $1.17-3.81$ \\
\hline \multirow[t]{2}{*}{ Max } & Matched OR & 2.23 \\
\hline & $95 \% \mathrm{Cl}$ & $1.18-4.21$ \\
\hline
\end{tabular}




\section{Discussion}

Our initial ProtoArray screening identified KIAA0513 as an antigen, as recognized by serum IgG in patients with atherosclerosis, and subsequently recombinant GST-tagged KIAA0513 protein of 301 amino acids was purified. Western blotting confirmed the presence of autoantibodies against KIAA0513 (Fig. 1). Using the KIAA0513 protein as an antigen, we examined serum antibody levels by AlphaLISA. The results showed significantly higher s-KIAA0513-Abs levels in the patients with AIS, TIA, DM, CVD, OSAS, CKD, EC, GC, CC, LC, and MC than in the HDs (Figs. 2-6, Table $1-5$ ). Among these diseases, the highest AUC values were observed for EC, type 2 CKD, and DM (Figs. 3, 5, and 6, Table 6). The close correlation between s-KIAA0513-Ab levels and HT (Table 7) might account for the association with OSAS, which is frequently accompanied by $\mathrm{HT}$ [47]. The Spearman's correlation analysis showed a significant correlation between s-KIAA0513-Ab and max-IMT, plaque score, and CAVI, all of which are indices of atherosclerosisrelated lesions (Table 8, Supplementary Table S2) [44-46]. In contrast, s-KIAA0513-Ab levels were weakly correlated with BS $(P=0.023)$ (Table 8$)$, but completely unrelated to HbA1c, a typical DM marker. Thus, although the patients with DM showed high s-KIAA0513-Ab levels compared with the HDs, this antibody marker might not primarily reflect DM lesions but rather atherosclerotic lesions caused by DM. Given that angiogenesis is essential for the development of cancer, vascular malformation might be accompanied by the typical alterations in atherosclerosis. In fact, DM and arteriosclerotic diseases are cancer risk factors [48-50].

There are 3 known splicing variants of KIAA0513: isoform a (411 amino acids, NP_055547.1), isoform b (301 amino acids, NP_001273495.1), and isoform c (301 amino acids, NP_001284695.1). The full-length 301 amino acids of KIAA0513 isoforms $c$ and $b$ are exactly the same as the first 301 amino acids of KIAA0513 isoform a. We also purified GST-fused KIAA0513 isoform a and examined the serum antibodies using sera from HDs and patients with AIS and CVD. Both isoforms a and $\mathrm{c}$ of KIAA0513 showed higher antibody levels in the sera from patients with AIS or CVD than in the sera from HDs (Supplementary Fig. $\mathrm{S} 1 \mathrm{a}$ and $1 \mathrm{~b}$ ). The reactivity of KIAA0513 isoform $\mathrm{c}$ against serum antibodies was closely correlated with that of KIAA0513 isoform a, although the former was higher than the latter (Supplementary Fig. S1c), implying that the major epitope sites of serum autoantibodies are located in the 301 amino acids of isoform c.

KIAA0513 mRNA expression has been observed predominantly in the neurons and glial cells of the brain, with low-level expression in most human tissues, whereas the KIAA0513 protein was exclusively found in the brain [43]. Among brain regions, the highest expression was in the cerebellum, cortex, hippocampus, pons, putamen, and amygdala. Using a yeast 2-hybrid analysis of a fetal brain cDNA library, Lauriat et al. [43] found that the N-terminal portion of KIAA0513 interacted with KIBRA, HAX1, and INTS4. A coimmunoprecipitation analysis revealed a physical association between KIAA0513 and KIBRA. Given that KIBRA, HAX1, and INTS4 are involved in synaptic and apoptotic signaling, KIAA0513 can also participate in these signaling pathways. 
In addition to the KIAA0513-Abs employed in this study, autoantibodies against ATP2B4, BMP-1, DHPS, LRPAP1, and ASXL2, which are markers of atherosclerosis, were also elevated in the sera of patients with EC $[7,8,11,12]$, indicating that arterial abnormalities can also affect the carcinogenic process. In fact, angiogenesis is essential for the development of solid tumors [51], and diabetes and obesity, which induce arteriosclerosis, are risk factors for CRC and EC [52-54]. Given that all tissues and organs require oxygen and nutrition provided by arteries, the alteration of arterial structure and/or function can affect numerous tissues and organs. All tissues and organs present in a body can affect each other to some degree [55]. In other words, the AIS, CVD, and CKD caused by arteriosclerosis, the arteriosclerosis induced by DM, and the solid cancer caused by arterial lesions can be accompanied by arterial abnormalities. Markers associated with such abnormalities could therefore detect all of the above disorders.

Cancer, heart disease, cerebrovascular disease, and renal failure are the first, second, fourth, and eighth leading causes of death in Japan, respectively (Ministry of Health, Labor and Welfare 2018 vital statistics). Most of the other causes of death are unavoidable, such as senility and accidents. In other words, the onset and progression of cancer, heart disease, cerebrovascular disease, and renal failure (as well as their risk factor DM) can be suppressed by proper health management, such as early diagnosis and intervention. Surprisingly, cancer, heart disease, cerebrovascular disease, renal failure, and DM can be detected by the s-KIAA0513-Ab marker, making it applicable for diagnostic purposes and providing appropriate treatment, lifestyle guidance, etc., leading to improved quality of life.

As of 2020, numerous reports have shown that the presence of underlying diseases such as DM, heart disease, cerebrovascular disease, cancer, OSA, and kidney disease aggravate the coronavirus disease (COVID-19) [56-59]. The s-KIAA0513-Ab marker is therefore a highly useful tool for detecting patients with a higher mortality risk in COVID-19.

Antibody markers are generally more sensitive than antigen markers. Given that the KIAA0513 protein has particularly high antigenicity, this KIAA0513-Ab marker is extremely sensitive. Given the major lifethreatening diseases this marker can detect, the KIAA0513-Ab marker could be referred to as a "supermarker".

\section{Conclusion}

The serum anti-KIAA0513 antibody marker appears to be useful for diagnosing the progress of atherosclerosis, which can lead to the onset of life-threatening AIS, CVD, and cancer.

\section{Abbreviations}

95\% Cls: 95\% Confidence intervals; AIS: Acute ischemic stroke; AMI: Acute myocardial infarction; AlphaLISA: Amplified luminescence proximity homogeneous assay-linked immunosorbent assay; Asympt-Cl: Asymptomatic ischemic stroke; AUC: Areas under the ROC curve; BC: Breast cancer; BMI: Body mass index; BS: Body sugar; CAVl: Cardio-ankle vascular index; $\mathrm{CCl}$ : Chronic-phase cerebral infarction; 
CKD: Chronic kidney disease; CRC: Colorectal cancer; CRP: C-reactive protein; CVD: Cardiovascular disease; DM: Diabetes mellitus; DSWMH: Deep and subcortical white matter hyperintensity; EC: Esophageal cancer; GC: Gastric cancer; GST: Glutathione S-transferase; HD: Healthy donor; HT: Hypertension; LC: Lung cancer; max-IMT: Maximum intima-media thickness; OR: Odds ratio; OSAS: Obstructive sleep apnea syndrome; PBS: Phosphate-buffered saline; ROC: Receiver operating characteristic; SD: Standard deviations; SEREX: Serological identification of antigens by cDNA expression cloning; TIA: Transient ischemic attack; UA: Unstable angina

\section{Declarations}

\section{Acknowledgments}

The authors would like to thank Prof. Masaki Takiguchi (Chiba University), Prof. Kenichiro Kitamura (Yamanishi University), Prof. Hao Wang (Jinan University), Dr. Xiao-Meng Zhang (Chiba University), Dr. Kazushige Katrura (RIKEN), and Dr. Noboru Ohsawa (RIKEN) for supporting this research as well as Ms. Seiko Otsuka, Masae Suzuki, Chiho Kusaka, Satoko Ishibashi, Chiemi Mishima-Tsumagari, Risa Kimura, Akiko Kimura, Ryo Fukushima, Yuko Ohta, and Aki Furuya for technical assistance.

\section{Authors' contributions}

TH, TMac, SYo, HK, HS, and YI conceived and designed the study. TH, SYL, MK, BSZ, NSh, and RN performed the experiments and acquired the data. SM, MSu, FS, MSh, SYo, MT, KY, YK, KM, SK, JT, KT, and HT contributed reagents, materials, analysis tools or patient data. YY, EK, TMat, and ST analyzed and interpreted the data. YY, MI, SYa, MSa, KY, HI, and NSa performed the statistical analyses. TH, YY, TMac, MSh, KY, and YI drafted the manuscript.

All authors gave final approval and agree to be accountable for all aspects of work ensuring integrity and accuracy.

All authors confirm that tables and figures were not published previously.

\section{Funding}

This work was supported, in part, by research grants from the Japan Science and Technology Agency (JST), JSPS KAKENHI Grant Number 20K17953, 19K09451, 17K19810, 19K08596, 20K07810, 16K10520, and 15K10117. The Japan Public Health Center-based Prospective Study was supported by National Cancer Center Research and Development Fund (since 2011) and a Grant-in-Aid for Cancer Research from the Ministry of Health, Labour and Welfare of Japan (from 1989 to 2010).

\section{Availability of data and materials}

The datasets used and/or analyzed during the current study are available from the corresponding author on reasonable request. 


\section{Ethics approval and consent to participate}

The present study was approved by the Local Ethical Review Board of Chiba University Graduate School of Medicine (Chiba, Japan) as well as the review boards of co-operating hospitals. Serum was collected from patients who had provided informed consent.

\section{Consent for publication}

Not applicable.

\section{Competing interests}

The present study was performed in collaboration with Fujikura Kasei Co., Ltd. RN, NS, and HK are employees of Fujikura Kasei Co., Ltd.

\section{References}

1. Kramer J, Harcos P, Prohászka Z, Horváth L, Karádi I, Singh M, et al. Frequencies of certain complement protein alleles and serum levels of anti-heat-shock protein antibodies in cerebrovascular diseases. Stroke. 2000;31:2648-52. PMID: 11062289

2. Machida T, Kubota M, Kobayashi E, Iwadate Y, Saeki N, Yamaura A, et al. Identification of strokeassociated-antigens via screening of recombinant proteins from the human expression cDNA library (SEREX). J Translat Med. 2015;13,71. doi: 10.1186/s12967-015-0393-4 PMID: 25890248

3. Goto K, Sugiyama T, Matsumura R, Zhang XM, Kimura R, Taira A, et al. Identification of cerebral infarction-specific antibody markers from autoantibodies detected in patients with systemic lupus erythematosus. J Mol Biomark Diagnos. 2015;6:2. doi.org/10.4172/2155-9929.1000219

4. Yoshida $\mathrm{Y}$, Wang H, Hiwasa T, Machida T, Kobayashi E, Mine S, et al. Elevation of autoantibody level against PDCD11 in patients with transient ischemic attack. Oncotarget 2018;9:8836-48. doi.org/10.18632/oncotarget.23653 PMID: 29507658

5. Wang H, Zhang XM, Tomiyoshi G, Nakamura R, Shinmen N, Kuroda $\mathrm{H}$, et al. Association of serum levels of antibodies against MMP1, CBX1, and CBX5 with transient ischemic attack and cerebral infarction. Oncotarget. 2018;9:5600-13. doi.org/10.18632/oncotarget.23789 PMID: 29464021

6. Yoshida Y, Zhang XM, Wang H, Machida T, Mine S, Kobayashi E, et al. Elevated levels of autoantibodies against DNAJC2 in sera of patients with atherosclerotic diseases. Heliyon. 2020;6: e04661. doi.org/10.1016/j.heliyon.2020.e04661 PMID: 32904265

7. Hiwasa T, Machida T, Zhang XM, Kimura R, Wang H, Iwase $K$, et al. Elevated levels of autoantibodies against ATP2B4 and BMP-1 in sera of patients with atherosclerosis-related diseases. Immunome Res. 2015;11:097. doi.org/10.4172/1745-7580.1000097

8. Nakamura R, Tomiyoshi G, Shinmen N, Kuroda H, Kudo T, Doi H, et al. An anti-deoxyhypusine synthase antibody as a marker of atherosclerosis-related cerebral infarction, myocardial infarction, 
diabetes mellitus, and chronic kidney disease. SM Atheroscler J. 2017;1:1001. doi:

http://smjournals.com/atherosclerosis/in-press.php\#x

9. Hiwasa T, Tomiyoshi G, Nakamura R, Shinmen N, Kuroda H, Kunimatsu M, et al. Serum SH3BP5specific antibody level is a biomarker of atherosclerosis. Immunome Res. 2017;13:132. doi: 10.4172/17457580.1000132

10. Zhang XM, Wang H, Mine S, Takemoto M, Yokote K, Kitamura K, et al. Association of serum antiprolylcarboxypeptidase antibody marker with atherosclerotic diseases accompanied by hypertension. J Mol Biomark Diagn. 2017;8:361. doi: 10.4172/2155-9929.1000361

11. Sumazaki M, Shimada H, Ito M, Shiratori F, Kobayashi E, Yoshida Y, et al. Serum anti-LRPAP1 is a common biomarker for digestive organ cancers and atherosclerotic diseases. Cancer Sci. 2020;111:4453-64. doi: 10.1111/cas.14652 PMID: 32939876

12. Li, SY, Yoshida Y, Kobayashi E, Adachi A, Hirono S, Matsutani T, et al. Association between serum anti-ASXL2 antibody levels and acute ischemic stroke, acute myocardial infarction, diabetes mellitus, chronic kidney disease and digestive organ cancer, and their possible association with atherosclerosis and hypertension. Int J Mol Med. 2020;46:1274-88. doi. 10.3892/ijmm.2020.4690 PMID: 32945427

13. Chen PM, Ohno M, Hiwasa T, Nishi K, Saijo S, Sakamoto J, et al. Nardilysin is a promising biomarker for the early diagnosis of acute coronary syndrome. Int J Cardiol. 2017;243:1-8. doi.org/10.1016/j.ijcard.2017.04.047 PMID: 28747015

14. Hiwasa T, Zhang XM, Kimura R, Machida T, Kitamura K, Yamazoe R, et al. Association of serum antibody levels against TUBB2C with diabetes and cerebral infarction. Integ Biomed Sci. 2015;1:4963. doi: $10.18314 /$ gjbs.v1i2.27

15. Palmer JP, Asplin CM, Clemons P, Lyen K, Tatpati O, Raghu PK, et al. Insulin antibodies in insulindependent diabetics before insulin treatment. Science. 1983;222:1337-9. doi:

10.1126/science.6362005 PMID: 6362005

16. Baekkeskov S, Aanstoot $H$, Christgau S, Reetz A, Solimena M, Cascalho M, et al. Identification of the $64 \mathrm{~K}$ autoantigen in insulin dependent diabetes as the GABA-synthesizing enzyme glutamic acid decarboxylase. Nature. 1990;347:151-6. doi: 10.1038/347151a0 PMID: 1697648

17. Hiwasa T, Zhang XM, Kimura R, Ohno M, Chen PM, Nishi E, et al. Elevated adiponectin antibody levels in sera of patients with atherosclerosis-related coronary artery disease, cerebral infarction, and diabetes mellitus. J Circ Biomark. 2016;5:8. doi: 10.5772/63218

18. Sugimoto K, Tomiyoshi G, Mori M, Kuwabara S, Hirano S, Sawai S, et al. Identification of serum antiGADD34 antibody as a common marker of diabetes mellitus and Parkinson disease. J Alzheimers Dis Parkinsonism. 2017;7:358. doi: 10.4172/2161-0460.1000358

19. Shimada H, Takeda A, Arima M, Okazumi S, Matsubara H, Nabeya Y, et al. Serum p53 antibody is a useful tumor marker in superficial esophageal squamous cell carcinoma. Cancer. 2000;89:1677-83. PMID: 11042560 
20. Shimada H, Ochiai T, Nomura F. Japan p53 Antibody Research Group. Titration of serum p53 antibodies in 1,085 patients with various types of malignant tumors: a multiinstitutional analysis by the Japan p53 Antibody Research Group. Cancer. 2003;97:682-9. PMID: 12548611

21. Nakashima K, Shimada H, Ochiai T, Kuboshima M, Kuroiwa N, Okazumi S, et al. Serological identification of TROP2 by recombinant cDNA expression cloning using sera of patients with esophageal squamous cell carcinoma. Int J Cancer. 2004;112:1029-35. doi: 10.1002/ijc.20517 PMID: 15386348

22. Kuboshima M, Shimada H, Liu TL, Nakashima K, Nomura F, Takiguchi M, et al. Identification of a novel SEREX antigen, SLC2A1/GLUT1, in esophageal squamous cell carcinoma. Int J Oncol. 2006;28:463-8. https://doi.org/10.3892/ijo.28.2.463 PMID: 16391802

23. Kuboshima M, Shimada H, Liu TL, Nomura F, Takiguchi M, Hiwasa T, et al. Presence of serum tripartite motif-containing 21 antibodies in patients with esophageal squamous cell carcinoma. Cancer Sci. 2006;97:380-6. doi: 10.1111/j.1349-7006.2006.00192.x PMID: 16630135

24. Shimada H, Kuboshima M, Shiratori T, Nabeya Y, Takeuchi A, Takagi H, et al. Serum anti-myomegalin antibodies in patients with esophageal squamous cell carcinoma. Int J Oncol. 2007;30:97-103. https://doi.org/10.3892/ijo.30.1.97 PMID: 17143517

25. Shimada H, Shiratori T, Yasuraok, M, Kagaya A, Kuboshima M, Nomura F, et al. Identification of Makorin 1 as a novel SEREX antigen of esophageal squamous cell carcinoma. BMC Cancer. 2009;9:232. doi:10.1186/1471-2407-9-232. PMID: 19604354

26. Kagaya A, Shimada H, Shiratori T, Kuboshima M, Nakashima-Fujita K, Yasuraoka M, et al. Identification of a novel SEREX antigen family, ECSA, in esophageal squamous cell carcinoma. Proteome Sci. 2011;9:31. doi:10.1186/1477-5956-9-31. PMID: 21696638

27. Shimada $H$, Ito $M$, Kagaya A, Shiratori T, Kuboshima M, Suzuki M, et al. Elevated serum antibody levels against cyclin L2 in patients with esophageal squamous cell carcinoma. J Cancer Sci Ther. 2015;7:60-6. doi:10.4172/1948-5956.1000326

28. Kobayashi S, Hoshino T, Hiwasa T, Satoh M, Rahmutulla B, Tsuchida S, e al. Anti-FIRs (PUF60) autoantibodies are detected in the sera of early-stage colon cancer patients. Oncotarget. 2016;7:82493503. doi: 10.18632/oncotarget.12696 PMID: 27756887

29. Kobayashi S, Hiwasa T, Ishige T, Rahmutulla B, Kano M, Hoshino T, et al. Anti-FIR $\Delta$ exon2, a splicing variant form of PUF60, auto-antibody is detected in the sera of esophageal squamous cell carcinoma. Cancer Sci. 2019;110:2004-13. doi: 10.1111/cas.14024. PMID: 30980774

30. Matsutani T, Hiwasa T, Takiguchi M, Oide T, Kunimatsu M, Saeki N, et al. Autologous antibody to srchomology 3-domain GRB2-like 1 specifically increases in the sera of patients with low-grade gliomas. J Exp Clin Cancer Res. 2012;31:85. doi:10.1186/1756-9966-31-85 PMID: 23050879

31. Adachi-Hayama M, Adachi A, Shinozaki N, Matsutani T, Hiwasa T, Takiguchi M, et al. Circulating antifilamin C antibody as a potential serum biomarker for low-grade gliomas. BMC Cancer. 2014;14:452. doi: 10.1186/1471-2407-14-452 PMID: 24946857 
32. Hontani K, Tsuchikawa T, Hiwasa T, Nakamura T, Ueno T, Kushibiki T, et al. Identification of novel serum autoantibodies against EID3 in non-functional pancreatic neuroendocrine tumors. Oncotarget. 2017;8:106206-21. doi: 10.18632/oncotarget.22175 PMID: 29290942

33. Matsumura T, Terada J, Kinoshita T, Sakurai Y, Yahaba M, Ema R, et al. Circulating anti-coatomer protein complex subunit epsilon (COPE) autoantibodies as a potential biomarker for cardio- and cerebro-vascular events in patients with obstructive sleep apnea. J Clin Sleep Med. 2017;13:393400. doi: 10.5664/jcsm.6488 PMID: 27923433

34. Matsumura T, Terada J, Kinoshita T, Sakurai Y, Yahaba M, Tsushima K, et al. Autoantibody against NBL1 in obstructive sleep apnea patients with cardiovascular disease. PLoS One. 2018;13:e0195015. doi: 10.1371/journal.pone.0195015 PMID: 29596467

35. Katsumata Y, Terada J, Matsumura T, Koshikawa K, Sakao S, Tomiyoshi G, et al. Circulating antisorting nexins 16 antibodies as an emerging biomarker of coronary artery disease in patients with obstructive sleep apnea. Diagnostics. 2020;10:71. doi: 10.3390/diagnostics10020071 PMID: 32012743

36. Adams HP Jr, Bendixen BH, Kappelle LJ, Biller J, Love BB, Gordon DL, et al. Classification of subtype of acute ischemic stroke. Definitions for use in a multicenter clinical trial. TOAST. Trial of Org 10172 in Acute Stroke Treatment. Stroke. 1993;24:35-41. doi: 10.1161/01.str.24.1.35 PMID: 7678184

37. Nishiura R, Fujimoto S, Sato Y, Yamada K, Hisanaga S, Hara S, et al. Elevated osteoprotegerin levels predict cardiovascular events in new hemodialysis patients. Am J Nephrol 2009;29:257-63. doi: 10.1159/000157629 PMID: 18802328

38. Komatsu H, Fujimoto S, Hara S, Fukuda A, Fukudome K, Yamada K, et al. Recent therapeutic strategies improve renal outcome in patients with IgA nephropathy. Am J Nephrol. 2009;30:19-25. doi: 10.1159/000197116 PMID: 19169006

39. Chumpolkulwong N, Sakamoto K, Hayashi A, Iraha F, Shinya N, Matsuda N, et al. Translation of "rare" codons in a cell-free protein synthesis system from Escherichia coli. J Struct Funct Genomics. 2006;7:31-6. PMID: 16703415

40. Tsugane S, Sawada N. The JPHC study: design and some findings on the typical Japanese diet. Jpn J Clin Oncol. 2014;44:777-82. doi: 10.1093/jjco/hyu096 PMID: 25104790

41. Ikeda A, Iso H, Sasazuki S, Inoue M, Tsugane S, JPHC Study Group. The combination of Helicobacter pylori- and cytotoxin-associated gene-A seropositivity in relation to the risk of myocardial infarction in middle-aged Japanese: The Japan Public Health Center-based study. Atherosclerosis. 2013;230:67-72. doi: 10.1016/j.atherosclerosis.2013.06.013 PMID: 23958254

42. Iso H, Noda H, Ikeda A, Yamagishi K, Inoue M, Iwasaki M, et al. The impact of C-reactive protein on risk of stroke, stroke subtypes, and ischemic heart disease in middle-aged Japanese: the Japan public health center-based study. J Atheroscler Thromb. 2012;19:756-66. doi https://doi.org/10.5551/jat.11999 PMID: 22785140

43. Lauriat TL, Dracheva S, Kremerskothen J, Duning K, Haroutunian V, Buxbaum JD, et al. Characterization of KIAA0513, a novel signaling molecule that interacts with modulators of 
neuroplasticity, apoptosis, and the cytoskeleton. Brain Res. 2006;1121:1-11. PMID: 17010949

44. Tran LT, Park HJ, Kim HD. Is the carotid intima-media thickness really a good surrogate marker of atherosclerosis? J Atheroscler Thromb. 2012;19:680-90. doi: 10.5551/jat.11767 PMID: 22653163

45. Zureik M, Ducimetière P, Touboul PJ, Courbon D, Bonithon-Kopp C, Berr C, et al. Common carotid intima-media thickness predicts occurrence of carotid atherosclerotic plaques: longitudinal results from the Aging Vascular Study (EVA) study. Arterioscler Thromb Vasc Biol. 2000;20:1622-9. doi: 10.1161/01.atv.20.6.1622 PMID: 10845881

46. Shirai K, Utino J, Otsuka K, Takata M. A novel blood pressure-independent arterial wall stiffness parameter; cardio-ankle vascular index (CAVI). J Atheroscler Thromb. 2006;13:101-7. PMID: 16733298

47. Floras JS. Hypertension and sleep apnea. Can J Cardiol. 2015;31:889-97. doi: 10.1016/j.cjca.2015.05.003 PMID: 26112299

48. Gallagher EJ, LeRoith D. Obesity and diabetes: The increased risk of cancer and cancer-related mortality. Physiol Rev. 2015;95:727-48. doi: 10.1152/physrev.00030.2014 PMID: 26084689

49. Goto A, Yamaji T, Sawada N, Momozawa Y, Kamatani Y, Kubo M, et al. Diabetes and cancer risk: A Mendelian randomization study. Int J Cancer. 2020;146:712-9. doi: 10.1002/ijc.32310 PMID: 30927373

50. Tapia-Vieyra JV, Delgado-Coello B, Mas-Oliva J. Atherosclerosis and cancer; A resemblance with farreaching implications. Arch Med Res. 2017;48:12-26. doi: 10.1016/j.arcmed.2017.03.005 PMID: 28577865

51. Makrilia N, Lappa T, Xyla V, Nikolaidis I, Syrigos K. The role of angiogenesis in solid tumours: an overview. Eur J Intern Med. 2009;20:663-71. PMID: 19818284

52. Jarvandi S, Davidson NO, Schootman M. Increased risk of colorectal cancer in type 2 diabetes is independent of diet quality. PLoS One. 2013;8:e74616 PMID: 24069323

53. Fujihara S, Kato K, Morishita A, Iwama H, Nishioka T, Chiyo T, et al. Antidiabetic drug metformin inhibits esophageal adenocarcinoma cell proliferation in vitro and in vivo. Int $\mathrm{J}$ Oncol. 2015;46:2172-80. PMID: 25709052

54. Berger NA. Young adult cancer: Influence of the obesity pandemic. Obesity (Silver Spring). 2018;26:641-50. PMID: 29570247

55. Hiwasa T, Shimada H. Autoantibody in Cancer. In: Shimada H, ed. Biomarkers in Cancer Therapy (ISBN: 978-981-13-7295-7), Singapore, Springer Nature, 2018;25-40. https://doi.org/10.1007/978981-13-7295-7_3

56. Zhou Y, Yang Q, Chi J, Dong B, Lv W, Shen L, et al. Comorbidities and the risk of severe or fatal outcomes associated with coronavirus disease 2019: A systematic review and meta-analysis. Int J Infect Dis. 2020;99:47-56. doi: 10.1016/j.ijid.2020.07.029 PMID: 32721533

57. Wu T, Zuo Z, Kang S, Jiang L, Luo X, Xia Z, et al. Multi-organ dysfunction in patients with COVID-19: A systematic review and meta-analysis. Aging Dis. 2020;11:874-94. doi: 10.14336/AD.2020.0520 PMID: 32765952 
58. Ye Q, Lu D, Shang S, Fu J, Gong F, Shu Q, et al. Crosstalk between coronavirus disease 2019 and cardiovascular disease and its treatment. ESC Heart Fail. 2020;7:3464-72. doi: 10.1002/ehf2.12960 PMID: 32935928

59. Maas MB, Kim M, Malkani RG, Abbott SM, Zee PC. Obstructive sleep apnea and risk of COVID-19 infection, hospitalization and respiratory failure. Sleep Breath. 2020:1-3. doi: 10.1007/s11325-02002203-0 PMID: 32989673

\section{Figures}

\section{Figure 1}

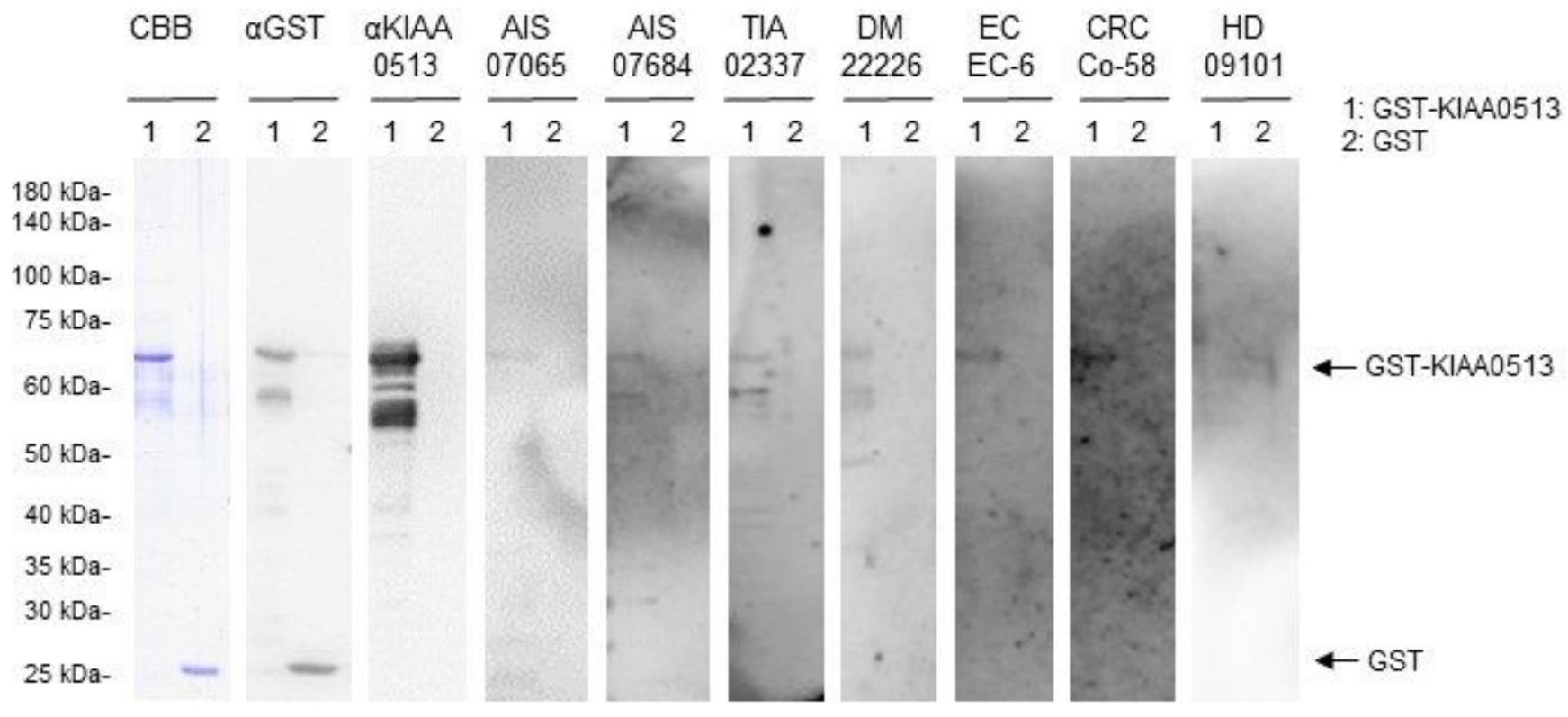

\section{Figure 1}

Presence of antibodies against KIAA0513 in sera from patient with acute ischemic stroke (AIS), transient ischemic attack (TIA), diabetes mellitus (DM), esophageal cancer (EC), or colorectal cancer (CRC). Purified proteins of GST-KIA0513 (lane 1) and GST (lane 2) were electrophoresed through sodium dodecyl sulfate-polyacrylamide gel, followed by staining with Coomassie Brilliant Blue (CBB) or western blotting using anti-GST (aGST), anti-KIAA0513 (aKIAA0513), serum IgG from patients with AIS (AIS-07065, AIS07684), TIA (TIA-02337), DM (DM-22226), EC (EC-6), or CRC (Co-58), and from a healthy donor (HD) (HD09101). 
Figure 2

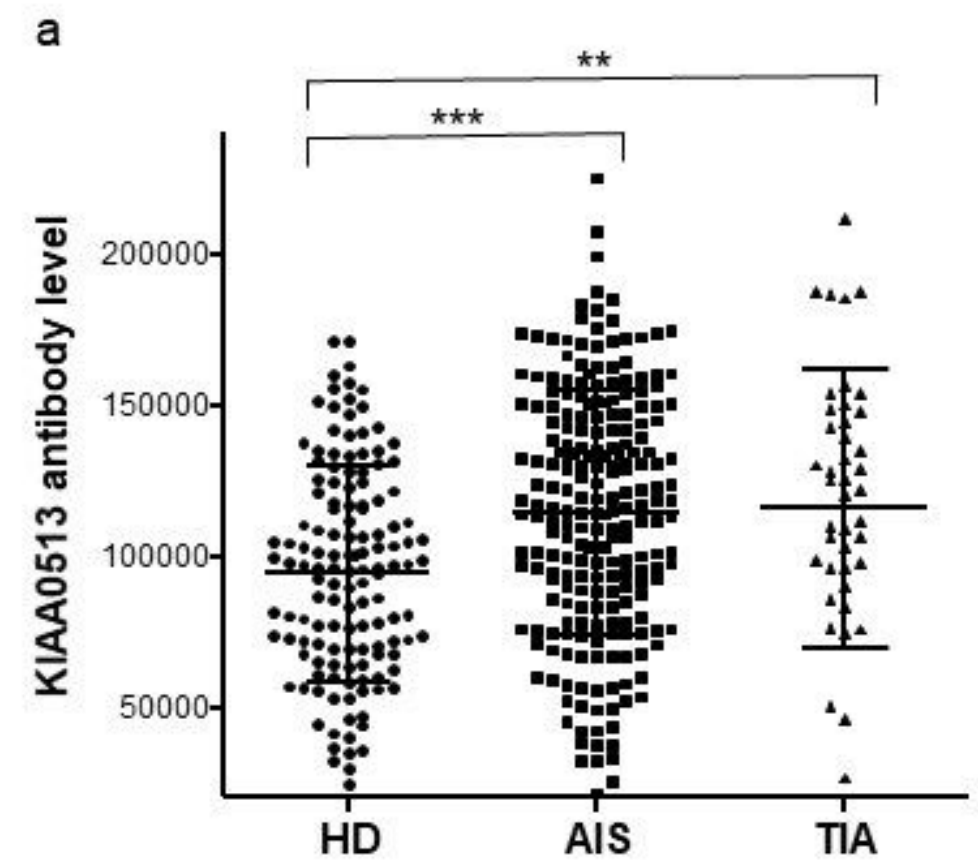

b

ROC: KIAA0513 vs AIS

c

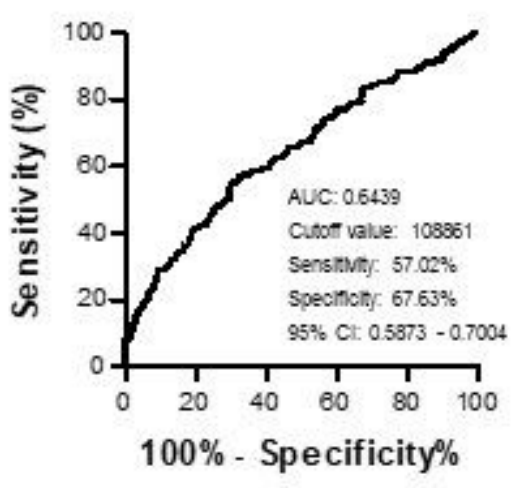

ROC: KIAA0513 vs TIA

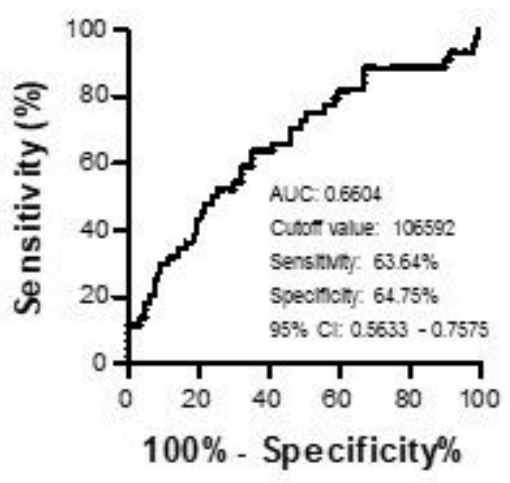

Figure 2

Comparison of serum anti-KIAA0513 antibody (s-KIAA0513-Ab) levels between HDs and patients with AIS or TIA. (a) The s-KIAA0513-Ab levels of healthy donors (HDs) and patients with AIS or TIA were examined by AlphaLISA using GST-KIAA05132-302 protein as the antigen, followed by subtraction of the levels against control GST. A scatter dot plot of the s-KIAA0513-Ab levels is shown. The bars represent the average and $\pm S D$. $P$ values were calculated using the Kruskal-Wallis test. $* *, P<0.01 ; * \star *, P<0.001$. The total (male/female) numbers, average ages \pm standard deviations (SDs), average antibody levels \pm SDs, 
cutoff values, positive numbers, positive rates (\%), and $\mathrm{P}$ values versus HDs are summarized and shown in Table 1. Receiver operating characteristic curve (ROC) analysis was performed to assess the abilities of s-KIAA0513-Abs to detect AIS (b) and TIA (c). Numbers in the figures indicate the areas under the curve (AUC), cutoff values for antibody levels, sensitivity, specificity, and $95 \%$ confidence interval $(95 \% \mathrm{Cl})$.

\section{Figure 3}

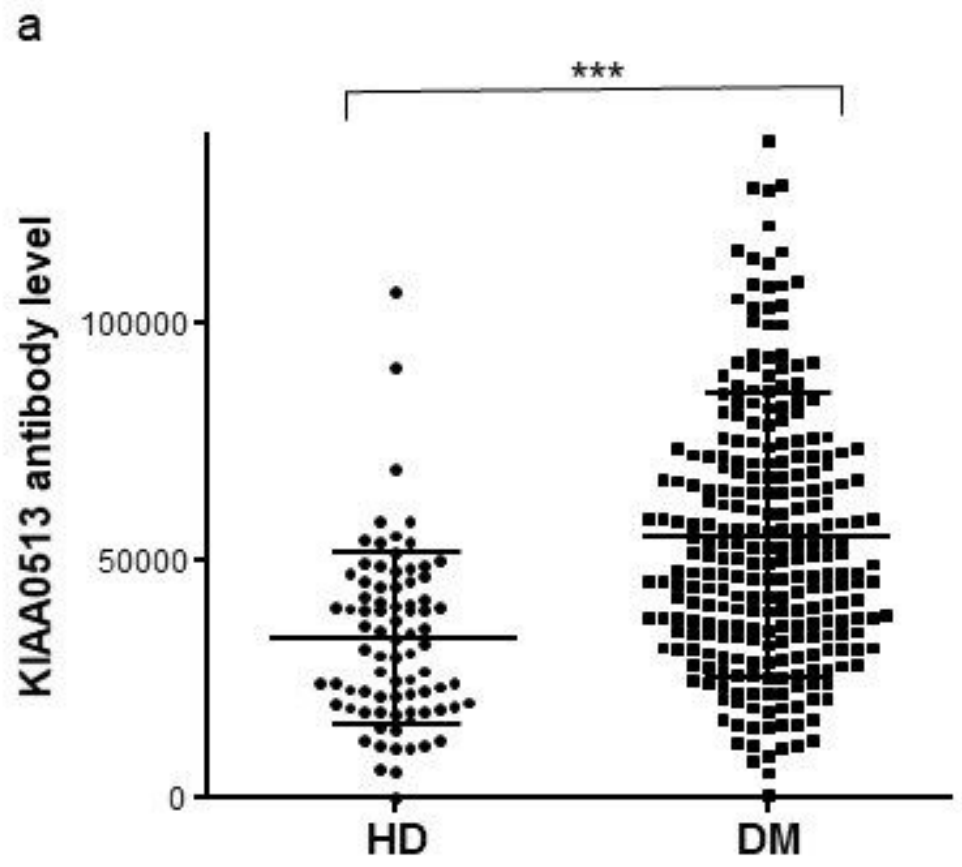

b

ROC: KIAA0513 vs DM

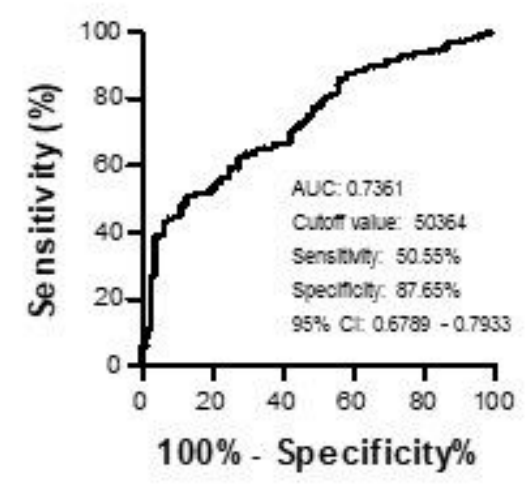

Figure 3

Comparison of s-KIAA0513-Ab levels between HDs and patients with DM. (a) GST-KIAA0513 protein was used as an antigen. Serum antibody levels in HDs and patients with DM were determined by AlphaLISA and are shown as a scatter dot plot, as described in the legend of Fig. 2. ${ }^{* *}, P<0.001$. The same results 
are summarized in Table 2. (b) Responses to s-KIAA0513-Abs was also evaluated using ROC analysis, and the numbers in figures are as described in the legend of Fig. 2.

Figure 4

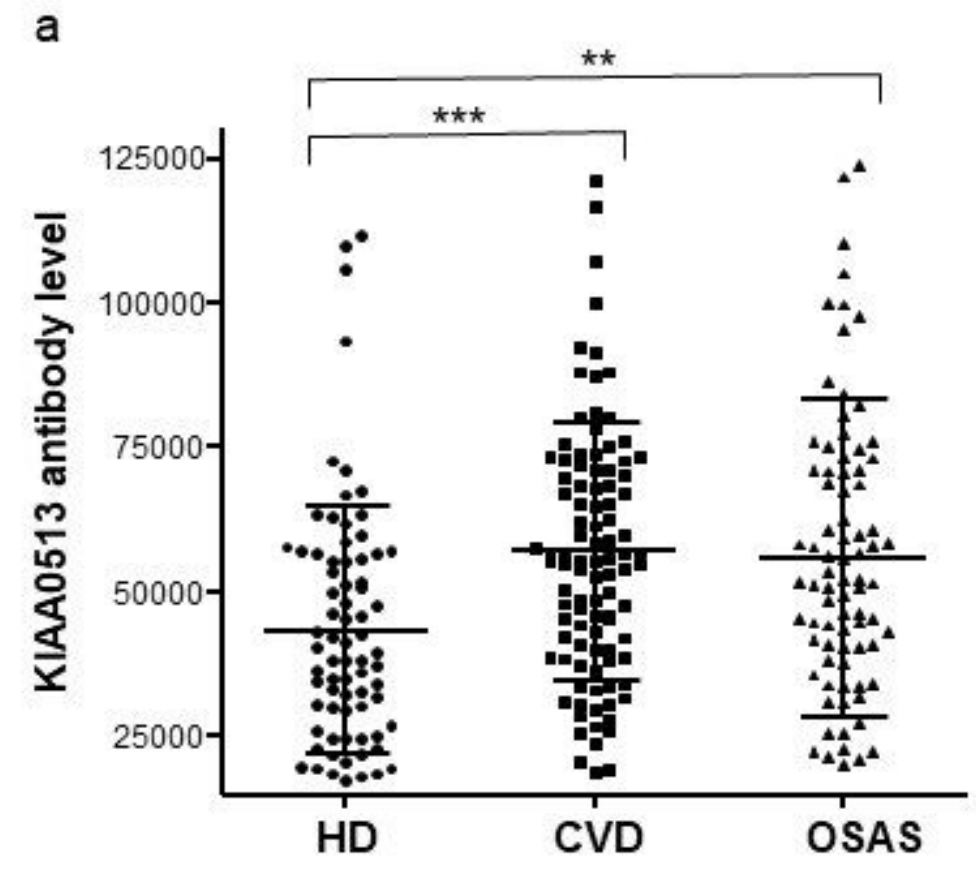

b

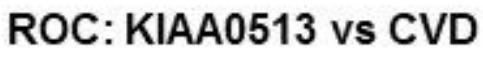

C

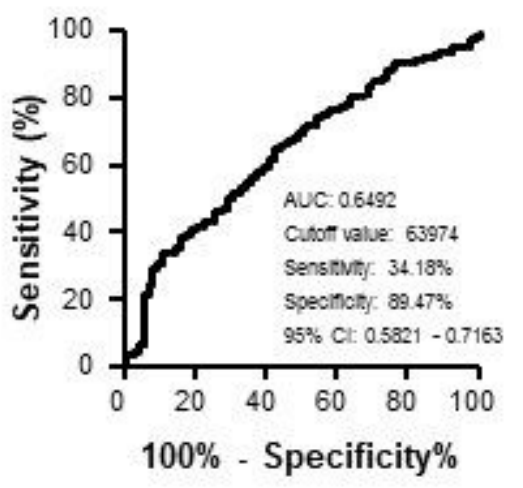

ROC: KIAA0513 vs OSAS

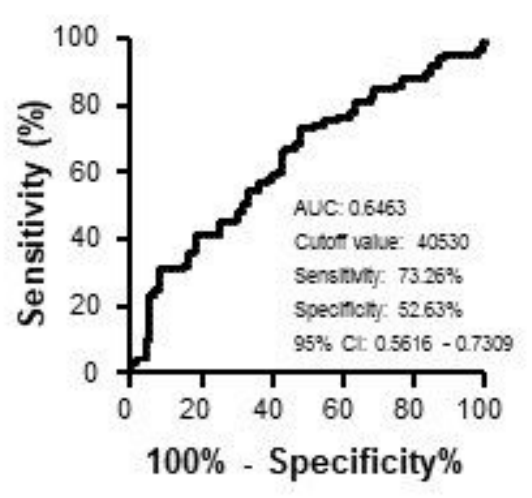

\section{Figure 4}

Comparison of s-KIAA0513-Ab levels between HDs and patients with cardiovascular disease (CVD) or obstructive sleep apnea syndrome (OSAS). (a) Serum antibody levels against KIAA0513 protein were examined by AlphaLISA and are shown as a scatter dot plot, as described in the legend of Fig. 2. **, $\mathrm{P}<$ 
$0.01 ; * \star \star, P<0.001$. The same results are summarized in Table 3 . The ability of s-KIAA0513-Abs to detect CVD (b) and OSAS (c) were also evaluated using ROC analysis as described in the legend of Fig. 2.

Figure 5

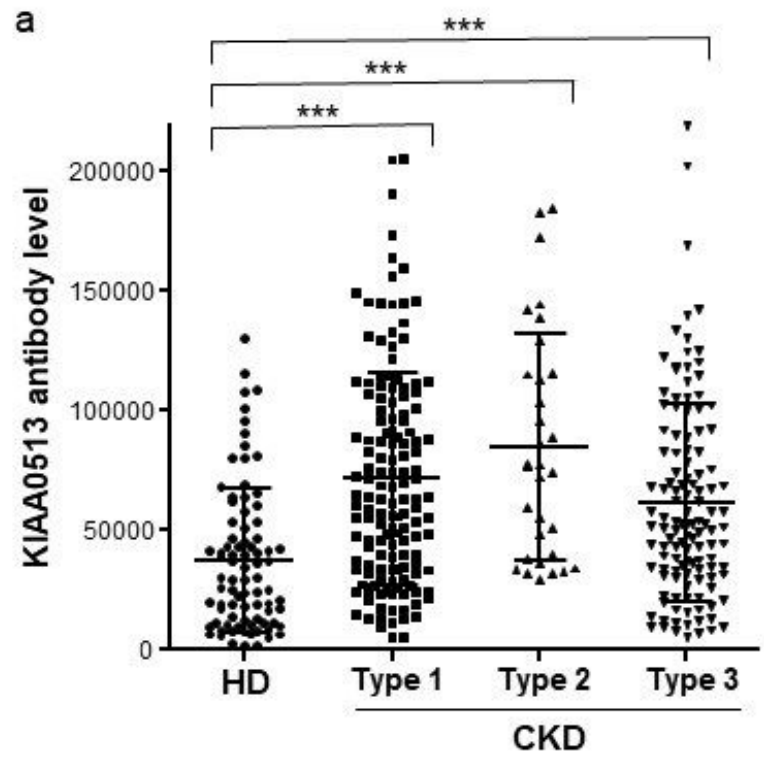

b

C

ROC: KIAA0513 vs Type-1 CKD

ROC: KIAA0513 vs Type-2 CKD
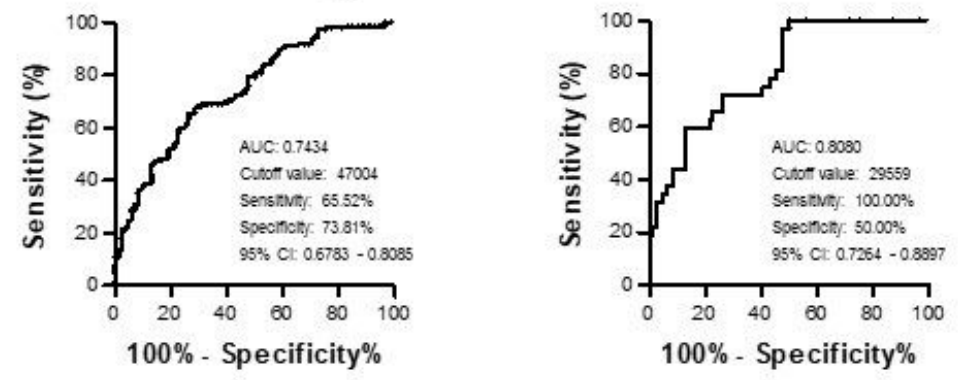

d

ROC: KIAA0513 vs Type-3 CKD

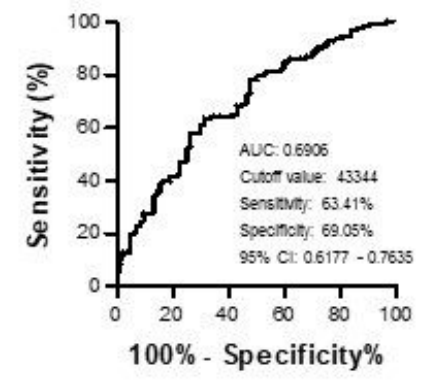

Figure 5

Comparison of s-KIAA0513-Ab levels between HDs and patients with chronic kidney disease (CKD). (a) Serum antibody levels against KIAA0513 protein were compared between HDs and patients with type-1, -2 , or -3 CKD and are shown as a scatter dot plot. Results are presented as described in the legend of Fig. 
2. $* \star \star, P<0.001$ vs. HD specimens. Averages, SDs, cutoff values, total numbers, positive numbers, positive rates (\%), and $P$ values are shown in Table 4. $(b-d)$ The abilities of s-KIAA0513-Abs to detect each type of CKD were also evaluated using ROC analysis.

Figure 6

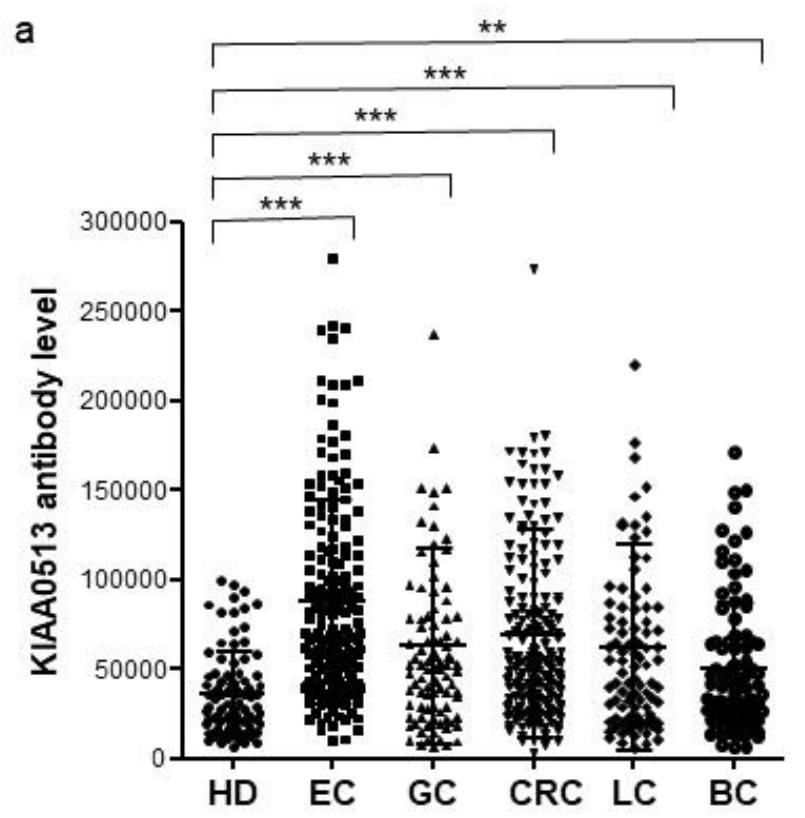

b

ROC: KIAA0513 vs EC

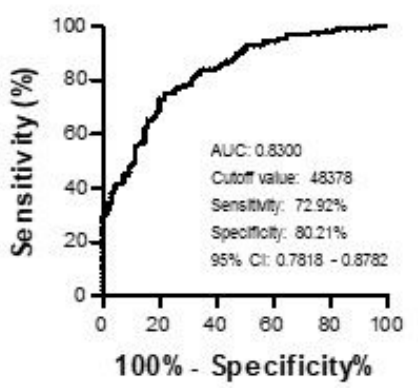

e

ROC: KIAA0513 vs LC

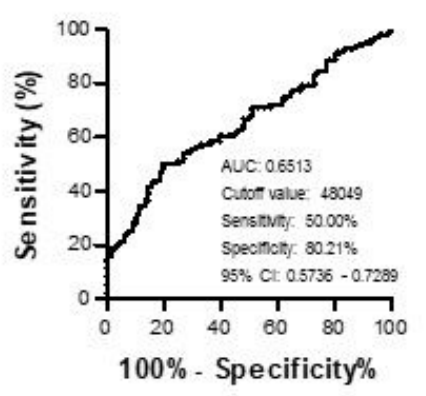

C ROC: KIAA0513 vs GC

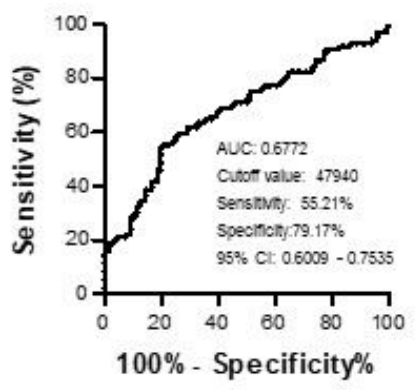

$f$

ROC: KIAA0513 vs BC

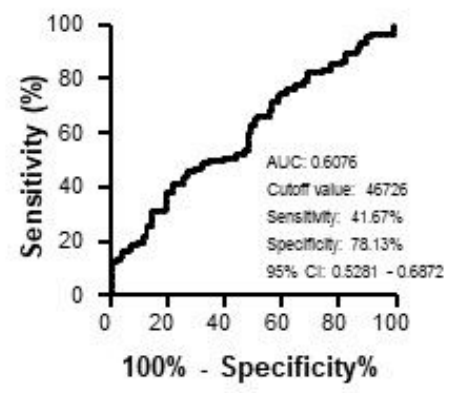

d

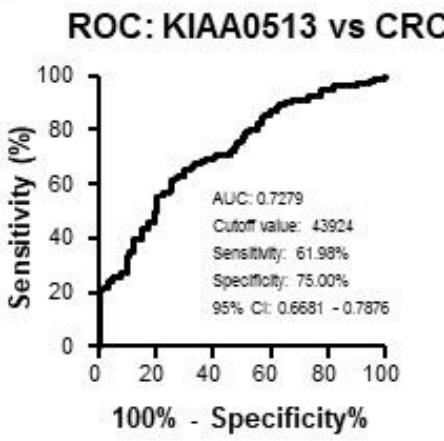

\section{Figure 6}

Comparison of s-KIAA0513-Ab levels between HDs and patients with EC, gastric cancer (GC), CRC, lung cancer (LC), or breast cancer (BC). (a) Serum antibody levels against KIAA0513 protein were compared 
between HDs and patients with cancer and are shown as a scatter dot plot. Results are presented as described in the legend of Fig. 2. ${ }^{\star *}, \mathrm{P}<0.01 ; * \star \star, P<0.001$ vs. HD specimens. Averages, SDs, cutoff values, total numbers, positive numbers, positive rates (\%), and $P$ values are summarized in Table 5 . (b-f) The abilities of s-KIAA0513-Abs to detect each cancer were also evaluated using ROC analysis.

Figure 7

a

EC

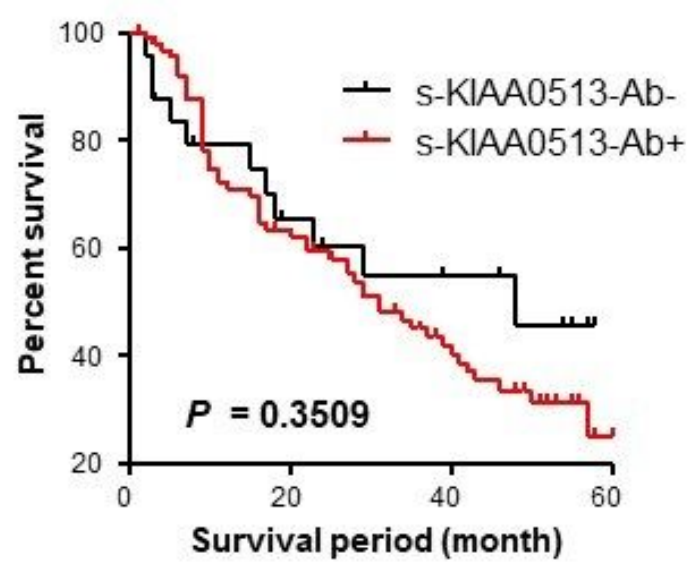

b GC

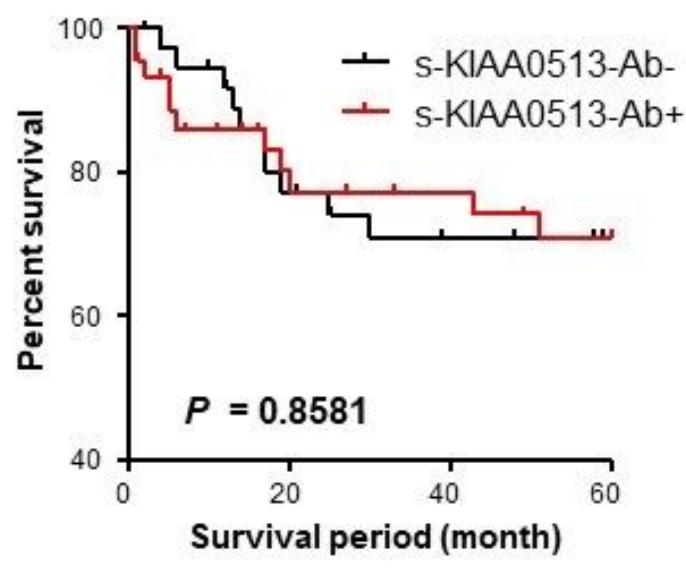

c

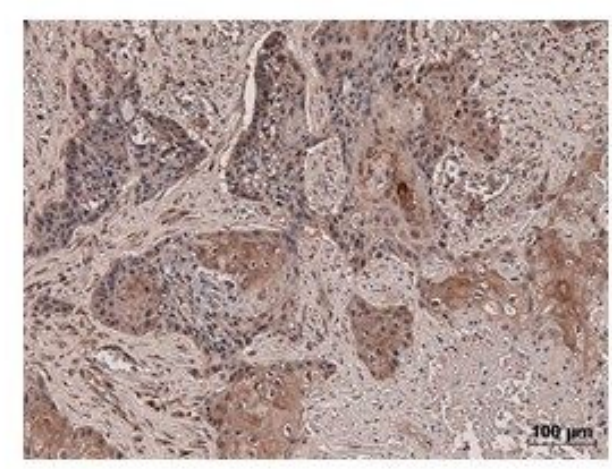

Figure 7 
Survival analysis and immunohistochemical staining of cancer specimens. Comparison of overall survivals of the patients with EC (a) or GC (b) according to s-KIAA0513-Ab-positive (s-KIAA0513-Ab+) and negative (s-KIAA0513-Ab-) groups. Cutoff values of EC and GC were determined by ROC analysis (Fig. 6b and $6 \mathrm{c}$, respectively). Statistical analyses were performed by the Log-Rank test. (c) Surgically resected EC tissue was stained using anti-KIAA0513 antibody (rabbit polyclonal antibodies, Atlas Antibodies).

\section{Supplementary Files}

This is a list of supplementary files associated with this preprint. Click to download.

- Additionalfile20210225.docx 